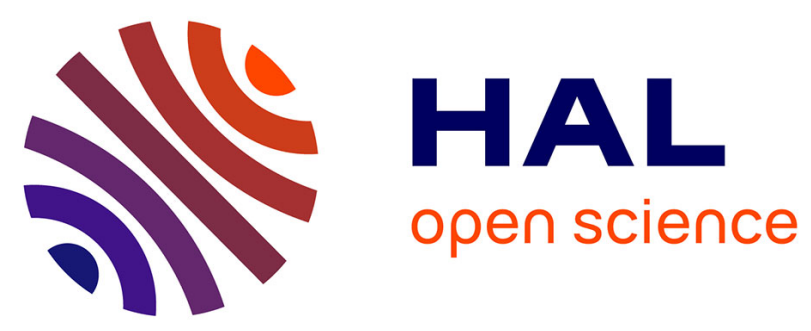

\title{
Development and structural characterization of a novel nanoemulsion for oral drug delivery
}

Annalisa Rosso, Giovanna Lollo, Yves Chevalier, Nam Troung, Claire Bordes, Sandrine Bourgeois, Ofelia Maniti, Thierry Granjon, Pierre-Yves Dugas, Sébastien Urbaniak, et al.

\section{To cite this version:}

Annalisa Rosso, Giovanna Lollo, Yves Chevalier, Nam Troung, Claire Bordes, et al.. Development and structural characterization of a novel nanoemulsion for oral drug delivery. Colloids and Surfaces A: Physicochemical and Engineering Aspects, 2020, 593, pp.124614. 10.1016/j.colsurfa.2020.124614 . hal-02841383

\section{HAL Id: hal-02841383 \\ https://hal.science/hal-02841383}

Submitted on 10 Dec 2020

HAL is a multi-disciplinary open access archive for the deposit and dissemination of scientific research documents, whether they are published or not. The documents may come from teaching and research institutions in France or abroad, or from public or private research centers.
L'archive ouverte pluridisciplinaire HAL, est destinée au dépôt et à la diffusion de documents scientifiques de niveau recherche, publiés ou non, émanant des établissements d'enseignement et de recherche français ou étrangers, des laboratoires publics ou privés. 


\section{Development and structural characterization of a novel nanoemulsion for oral drug delivery}

Annalisa Rosso ${ }^{1}$, Giovanna Lollo ${ }^{1}$, Yves Chevalier ${ }^{1}$, Nam Troung $^{1}$, Claire Bordes ${ }^{1}$, Sandrine Bourgeois ${ }^{1}$, Ofelia Maniti ${ }^{2}$, Thierry Granjon ${ }^{2}$, Pierre-Yves Dugas ${ }^{3}$, Sebastien Urbaniak ${ }^{1}$, Stephanie Briançon ${ }^{1}$

${ }^{1}$ University of Lyon, Université Claude Bernard Lyon 1, CNRS, LAGEPP UMR 5007, 43 bd 11 Novembre 1918, 69622 Villeurbanne, France.

2 University of Lyon, Université Lyon 1, CNRS, Institut de Chimie et Biochimie Moléculaires et Supramoléculaires, ICBMS UMR 5246, 43 bd 11 Novembre 1918, 69622 Villeurbanne, France.

${ }^{3}$ University of Lyon, Université Lyon 1, CNRS, C2P2 UMR 5265, 43 bd 11 Novembre 1918, 69622 Villeurbanne, France.

\section{Abstract}

The objective of this work has been to develop a template for the design and characterization of dried nanoemulsion (NE) for oral administration of hydrophobic compounds. A rational optimization of the nanosystem using an experimental design was performed to achieve stable NE of $100 \mathrm{~nm}$ with a neutral surface potential. NE were able to efficiently encapsulate the model drug tacrolimus, providing a sustained drug release in both SGF (simulated gastric fluid) and FaSSIF-V2 fluid (simulated intestinal fluid in fasted state). To improve their long-term physical stability, NE were dried using spray-drying and freeze-drying. Following reconstitution in water, they maintain their physicochemical properties without alteration. The highest process yield was obtained by freezedrying using very low amount of cryoprotectant, overcoming major challenges related with the production of dry powders from oil based systems. Then, in order to improve the current structural analysis of nanocarriers an original structural characterization of the NE, with an in-depth focus on the NE shell nature was then performed. Through X-ray diffraction and differential scanning calorimetry (DSC) measurements we demonstrated that the NE shell was amorphous when in colloidal suspension and crystalline upon drying. We also developed a novel polarity-sensitive fluorophore to assess the NE shell fluidity when in colloidal suspension. Globally, in the work here presented a relationship between the fluidity of the NE shell and the structure of used excipients was established. The gained evidences on the NE structure will contribute to a more rational design of nanosystems, opening the way to novel applications in oral drug delivery.

\section{II.1. Introduction}

Lipid-based drug delivery systems (LBDDS) have drawn increasing attention in the last decade for their great potential to improve oral delivery of poorly water-soluble drugs [1]. Their main advantages rely on the ability i) to increase the solubility of hydrophobic compounds, ii) to protect the associated drug from the harsh conditions of the GI tract, iii) to prolong drug intestinal residence time and iv) to promote interactions with intestinal epithelium resulting in enhanced intestinal absorption [2]. Moreover, they can be obtained using easy and transposable techniques of production that allow the translation of LBDDS to pre-clinical studies and clinical applications. 
LBDDS are core-shell structures composed of an inner oil core in which the drug is solubilized and an external layer which stabilizes the aqueous suspension. They are made of inert, biocompatible and biodegradable FDA-approved materials having well-established safety profiles for oral administration of pharmaceuticals [3]. LBDDS include a wide range of nanosystems that can be classified as: vesicular systems (i.e. liposomes, niosomes), fluid emulsified systems such as nanoemulsions (NE) and self-emulsifying drug delivery systems (SEDDS), and solid lipid particulate systems such as solid lipid nanoparticles (SLN), nanostructured lipid carrier (NLC) and lipid nanocapsules (LNC) [4,5]. All these LBDDS are structurally different though they are based on emulsion formulation processes. Thus, mastery over emulsion formation phenomena is crucial towards the development of nanosystems having definite specifications of their therapeutic properties depending on the drug to be loaded [6].

NE are thermodynamically unstable emulsions with mean droplet diameters lower than $200 \mathrm{~nm}$ made of an inner oil core stabilized by an external surfactant shell [7]. Their advantage over other LBDDS arises from the large drug loading capacity provided by the high oil content of the system [810]. NE can be obtained using either high-energy or low-energy approaches. These methods differ for the physicochemical mechanisms that govern nanosystem formation. High-energy approaches are based on the use of specific equipment (high-pressure homogenizers, ultrasound dispersers) that dissipate intense mechanical power into the sample, mixing water and oil phases and breaking droplets down to smaller sizes [11]. In contrast, low-energy approaches relying on "spontaneous emulsification" processes, such as the phase inversion composition (PIC), emulsion phase inversion (EPI), and phase inversion temperature (PIT) techniques which allow the formation of ultrafine droplets $[8,12]$. Among low-energy approaches, EPI method is an isothermal technique in which emulsification is performed by changes in system composition [13]. It has been widely studied for the production of NE $[6,8,13,14]$. However, major drawbacks such as the limited types of surfactants which can be used compared to high-energy method and the propensity to Ostwald ripening due to the high Laplace pressure inside small NE droplets, limits the use of EPI technique for the production of suitable NE [15].

Based on the previous background, the present work aims at the rational design and development of a novel NE. The EPI technique and homogenization process were combined to broaden the spectra of excipients that can be used to formulate NE by low energy methods. A case-specific optimization of the system was performed using an experimental design. The influence of composition (surfactant amount and surfactant-to-oil ratio SOR) on physicochemical properties of NE was study. The transposability of the system was evaluated and the optimized NE formulation was scaled up 10-fold. Tacrolimus, a BCS Class II immunomodulatory agent used in the treatment of various diseases, was chosen as hydrophobic model drug to be encapsulated into NE. Stability studies and in vitro release behaviour were carried out in relevant GI media as simulated gastric fluid (SGF) and simulated intestinal fluid in fasted state (FaSSIF-V2). The procedure here presented for nanoemulsion formulation and characterization can be used as template for a rational design of lipid nanosystems. 
Then, NE were dried using spray-drying and freeze-drying to preserve their long term stability. While NE formulations have already been reported for oral drug delivery, to our knowledge, drying processes to obtain a powder as final product are still lacking in the literature [32,33].

The shell surrounding NE droplets was characterized exploiting a unique methodology. X-ray diffraction and differential scanning calorimetry (DSC) were used to assess the shell crystalline or amorphous state. Finally, an innovative method based on a specific fluorescence spectroscopy analysis by labelling NE with a Laurdan derivative, was set up to investigate the shell fluid or rigid nature. The ultimate goal was to offer a way of correlating the shell composition and rigidity with nanoparticle stability, drug encapsulation efficacy and release behaviour.

\section{II.2. Materials and methods}

\section{II.2.1. Materials}

Medium chain triglycerides, MCT (Miglyol ${ }^{\circledR} 812$ ) purchased from CREMER OLEO GmbH \& Co. KG (Hamburg, Germany) was used as oil. Polyoxyethylene(40) stearate (Myrj ${ }^{\circledR 52}$ ) from Sigma-Aldrich (St Quentin-Fallavier, France) and oleoyl polyoxyl-6 glycerides (Labrafil ${ }^{\circledR}$ M1944CS) from Gattefossé (Saint-Priest, France) were used as non-ionic surfactants. The aqueous phase used to prepare emulsions was sodium phosphate buffer solution ( $5 \mathrm{mM}$; $\mathrm{pH}$ 7.4). Tacrolimus was purchased from LC Laboratories (Woburn, MA, USA). Hydrochloric acid 37\%, AnalaR NORMAPUR ${ }^{\circledR}$ Reag. Ph. Eur. was from VWR International (Fontenay-sous-Bois, France). Dichloromethane, methanol, acetonitrile (HPLC grade), dodecyl sulfate sodium salts pure, sodium taurocholate hydrate $96 \%$ and sodium hydroxide were purchased from Fisher Scientific (Illkirch, France). Egg phospholipids with 70\% phosphatidylcholine (Lipoid E80S) was from Lipoid GmbH (Ludwigshafen am Rhein, Germany). Acetic acid was obtained from Chem-Lab NV (Zedelgem, Belgium). Maltodextrin MD (Glucidex ${ }^{\circledR}$ 12D) from Roquette Frères (Lestrem, France) and trehalose 100 (TR) as a gift of Hayashibara Co. Ltd (Okayama, Japan) were used as cryoprotectants in the drying studies. Milli-Q water, used to prepare all solutions and buffers, was obtained using a Milli-Q Academic System (Millipore, Saint Quentin, Yvelines France).

\section{II.2.2. Nanoemulsion preparation}

Nanoemulsions (NE) were prepared by emulsion phase inversion (EPI) technique [13]. The oil phase was prepared by mixing the oil (MCT) and surfactants (Polyoxyethylene(40) stearate: S1 and oleoyl polyoxyl-6 glycerides: S2) under magnetic stirring $(750 \mathrm{rpm})$ at $80^{\circ} \mathrm{C}$. Then, the aqueous phase (PBS $5 \mathrm{mM}$ ), heated at $80{ }^{\circ} \mathrm{C}$ as well, was added all at once into the organic melt phase. Stirring was performed using a rotor-stator disperser (T25 digital Ultra-Turrax ${ }^{\circledR}$ equipped with a S25N-8G shaft. IKA $^{\circledR}$-Werke GmbH \& Co. KG, Staufen, Germany) at 11,000 rpm. The resulting colloidal system was cooled to room temperature under magnetic stirring during $30 \mathrm{~min}$. The process was designed so that the final emulsion always had a total mass of $5 \mathrm{~g}$. Finally, NE were scaled up to $50 \mathrm{~g}$ (10 times larger than the optimization step scale) by adaptation of the shaft of the rotor-stator disperser. 


\subsubsection{Influence of formulation: ternary phase diagram and mixture design}

To investigate the NE region, three ternary phase diagrams were designed using 23 formulations for each diagram. The ternary mixtures were composed of oil, water and three different surfactant mixtures ( $\mathrm{S} 1+\mathrm{S} 2$ ) called Smix. Smix was characterized by the Surfactant Mass Ratio (SMR) of S1 to S2

$S M R=\frac{\text { mass of } \mathrm{S} 1}{\text { mass of } \mathrm{S} 2}$ Eq. 1

The NE area was identified by varying the Smix/Oil/Water amount at fixed $S M R$ of 1, 2.5, and 5. Another parameter of the formulation was the Surfactant-to-Oil ratio (SOR) defined as $S O R=\frac{\text { mass of Smix }}{\text { mass of MCT }}$ Eq. 2

\section{II.2.3. Physicochemical and morphological measurements}

Electrical conductivity was measured using a portable conductivity meter (CDM210 Conductivity Meter, MeterLabTM, Radiometer Analytical SAS, Lyon, France). Shear viscosity measurements were performed using a controlled shear-rate rheometer (MCR 302 rheometer, Anton Paar, Les Ulis, France). All measurements were carried over a range of different shear rates $\left(0.1-100 \mathrm{~s}^{-1}\right)$ at $25{ }^{\circ} \mathrm{C}$. The crystalline characteristics of NE were determined through X-ray powder diffraction (XRPD) analysis at the "Centre de Diffractométrie Henri Longchambon" facility of the University Lyon 1 using a Bruker AXS D8 Advance X-ray diffractometer operating in the Bragg $\theta-2 \theta$ configuration using $\mathrm{Cu} \mathrm{K} \alpha$ radiation (1.54 $\AA$ wavelength) in an angular domain from $10^{\circ}$ to $70^{\circ}$ at scanning rates of $0.25^{\circ} \cdot \mathrm{min}^{-1}$. Size distribution and surface electrical potential of NE were measured using Malvern Zetasizer ${ }^{\circledast}$ NanoZS (Malvern Instruments S.A., Worcestershire, UK). Particle size and polydispersity index (PdI) were determined by Dynamic Light Scattering (DLS) diluting all samples with Milli-Q water to ensure correct calculation of size distribution by the method of cumulants. Analyses were carried out at 25 ${ }^{\circ} \mathrm{C}$ with an angle of detection of $173^{\circ}$. $\zeta$-potentials were measured by electrophoresis technique after dilution of samples in $\mathrm{KCl} 1 \mathrm{mM}$. Analyses were performed in triplicate.

NE morphology was analysed by transmission electron microscopy (TEM), cryogenic-transmission electron microscopy (Cryo-TEM) and scanning electron microscopy (SEM) at the "Centre Technologique des Microstructures" (CT $\mu$ ) facility of the University of Lyon. TEM was performed with a Philips CM120 microscope. Diluted NE $(10 \mu \mathrm{L})$ was deposited on a microscope grid (copper support coated with carbon) and slowly dried in open air. The dry samples were observed by TEM under $120 \mathrm{kV}$ acceleration voltage. For Cryo-TEM analysis diluted samples of NE were dropped onto 300 mesh holey carbon films (Quantifoil R2/1) and quench-frozen in liquid ethane using a cryoplunge workstation (made at Laboratoire de Physique des Solides-LPS, Orsay, France). The specimens were then mounted on a precooled Gatan 626 sample holder, transferred into the microscope (Phillips CM120) and observed at an accelerating voltage of $120 \mathrm{kV}$. Moreover, TEM microscope grids, on which NE were deposited and slowly dried in open air overnight, were plunged frozen in liquid ethane (following the Cryo-TEM protocol of sample preparation) and NE were observed by TEM (cold TEM).

Scanning electron microscopy (SEM) was performed on dried samples following spray-drying with a FEI Quanta 250 FEG microscope. A drop of diluted aqueous suspension of re-hydrated spray-dried NE 
was deposited on a flat steel holder and dried at room temperature. Then samples were coated under vacuum by cathodic sputtering with copper. The samples were observed by SEM under an accelerating voltage of $15 \mathrm{kV}$.

The structural characterizations of NE aqueous suspensions and dried NE were performed by differential scanning calorimetry (DSC) using a Q200 ${ }^{\circledR}$ instrument from TA Instruments (New Castle, $\mathrm{DE}, \mathrm{USA}$ ). A nitrogen purge of $50 \mathrm{~mL} \cdot \mathrm{min}^{-1}$ was used for all measurements. The temperature range was $-80{ }^{\circ} \mathrm{C}$ to $+160{ }^{\circ} \mathrm{C}$. Samples (about $10 \mathrm{mg}$ ) were accurately weighed and sealed in $40 \mu \mathrm{L}$ aluminium pans close with either a hermetic lid for DSC of excipients and NE powders, or perforated aluminium lids DSC of NE and S1 in water that gradually released water when heated above $40{ }^{\circ} \mathrm{C}$.

The fluidity of the NE shell was determined by mean of a newly synthesized Laurdan derivative, Dioll (patent pending EPO19306175.1-1118). The Dioll probe was dissolved in ethanol (263 $\mu \mathrm{M})$. NE was diluted 1:100 $(0.27 \% \mathrm{w} / \mathrm{v})$. The Dioll solution $(10 \mu \mathrm{L})$ was added to $1 \mathrm{~mL} \mathrm{NE}$ to reach a $2.6 \mu \mathrm{M}$ final concentration of Dioll, corresponding to a Dioll-NE ratio of 1:2900 (w/w). The sample was incubated for $20 \mathrm{~min}$ at room temperature. As controls, the fluorescence of Dioll solutions ( $2.6 \mu \mathrm{M})$ in MCT and in water, and the fluorescence of blank NE (without Dioll) were recorded. For the blank NE control, $10 \mu \mathrm{L}$ of ethanol were added to $1 \mathrm{~mL}$ NE. Fluorescence data were obtained using a FP-8500 spectrofluorimeter (JASCO applied science, Halifax, Canada). The excitation wavelength was $390 \mathrm{~nm}$ and the emission spectra were recorded between 400 and $600 \mathrm{~nm}$ at several temperatures ranging from 5 to $27^{\circ} \mathrm{C}$ in steps of $2{ }^{\circ} \mathrm{C}$ and at $37^{\circ} \mathrm{C}$ ( $2.5 \mathrm{~nm}$ bandwidth). The generalized polarization (GP) parameter was calculated from emission intensities according to:

$G P=\frac{I_{440-} I_{490}}{I_{440+} I_{490}}$

Eq. 3

where $I_{440}$ and $I_{490}$ are recorded fluorescence intensities at wavelengths of $440 \mathrm{~nm}$ and $490 \mathrm{~nm}$, respectively, as previously described for Laurdan [16].

\section{II.2.4. Tacrolimus-loaded nanoemulsion development}

\section{II.2.4.1. Solubility study of tacrolimus}

Tacrolimus (50 mg) was dissolved in $1 \mathrm{~mL}$ of MCT, S2 or S1, stirred $\left(750 \mathrm{rpm}\right.$ ) at $80^{\circ} \mathrm{C}$ during $3 \mathrm{~h}$ and left overnight to reach equilibrium.

Then, samples were centrifuged at $14000 \mathrm{rpm}$ for $20 \mathrm{~min}$ and the supernatant was collected and mixed with $1 \mathrm{~mL}$ of a methanol-dichloromethane mixture (1:1) and $2 \mathrm{~mL}$ of acetonitrile. Following filtration with $0.22 \mu \mathrm{m}$ Nylon syringe filter (Whatman $\mathrm{GmbH}$, Dassel, Germany), samples were injected into the HPLC system for tacrolimus detection. The apparatus consisted of Agilent 1200 Series G1311A Quat Pump, Agilent 1200 Series G1367B HIP-ALS High Performance Autosampler, equipped with Agilent 1200 Series G1315D Dad Diode Array Detector HPLC (Agilent, Santa Clara, CA, United States). Tacrolimus was separated on a RP-C18 column (Kinetex $5 \mu \mathrm{m} \mathrm{C18} 100 \AA$, $150 \times 4.6 \mathrm{~mm}$, Phenomenex, Torrance, CA, USA), with temperature set to $60^{\circ} \mathrm{C}$, using acetonitriledeionized water $0.5 \%$ acetic acid (70:30) as mobile phase at a flow rate of $1.0 \mathrm{~mL} \cdot \mathrm{min}^{-1}$. The injection volume was $20 \mu \mathrm{L}$ and the detection wavelength was $213 \mathrm{~nm}$ [17]. The retention time of tacrolimus was at $3.99 \pm 0.02 \mathrm{~min}$. The system was managed by OpenLab CDS ChemStation Edition software 
(Agilent, Santa Clara, CA, United States). The calibration curve was linear $\left(R^{2}=0.999\right)$ in the concentration range of $10-250 \mu \mathrm{g} \cdot \mathrm{mL}^{-1}$. The method was validated according to ICH Q2(R1) guidelines. Detection and quantification limits ( $L O D$ and $L O Q$ ) were $7.6 \mu \mathrm{g} \cdot \mathrm{mL}^{-1}$ and $23 \mu \mathrm{g} \cdot \mathrm{mL}^{-1}$, respectively [18].

\section{II.2.4.2. Tacrolimus encapsulation efficiency and drug loading in nanoemulsions}

To determine the encapsulation efficiency $(E E)$ of tacrolimus into the system, tacrolimus-loaded NE $\left(2 \mathrm{mg} \cdot \mathrm{mL}^{-1}\right.$ ) was separated from the aqueous medium by size exclusion chromatography. Separation was performed on PD-10 Desalting Columns, containing $8.3 \mathrm{~mL}$ of Sephadex ${ }^{\mathrm{TM}} \mathrm{G}-25$ resin (GE Healthcare Bio-Sciences AB, Uppsala, Sweden), using BPS $5 \mathrm{mM}$ as the eluent. Fractions containing NE were identified and collected in microtubes owing to their milky appearance. Tacrolimus was extracted from fractions containing NE as previously described (section 2.4.1) and analysed by HPLC. Total NE was analysed to determine the total amount of tacrolimus present in the initial formulation. The encapsulation efficiency $(E E)$ was calculated following Eq. 4:

$E E(\%)=\frac{\text { mass of tacrolimus in } \mathrm{NE}}{\text { mass of tacrolimus feeding }} \times 100 \quad$ Eq. 4

The drug loading $(D L)$ was calculated as the ratio of the mass of tacrolimus detected in the purified NE to the total mass of NE:

$D L(\%)=\frac{\text { mass of tacrolimus in } \mathrm{NE}}{\text { mass of } \mathrm{NE}} \times 100 \quad$ Eq. 5

Analyses were done in triplicate.

\section{II.2.5. In vitro NE stability and release study of tacrolimus in simulated GI fluids}

The simulated gastric fluid (SGF, pH 1.2, 0.5\% Sodium Lauryl Sulfate (SLS)) and simulated intestinal fluid in fasted state (FaSSIF-V2, pH 6.5) were prepared according to Zhang et al. [19] and Jantratid et al. [20] respectively. The colloidal stability of tacrolimus-loaded NE in simulated gastric and intestinal fluids was evaluated by DLS analysis. To this aim, $250 \mu \mathrm{L}$ of NE were diluted in $1 \mathrm{~mL}$ of either simulated gastric fluid without pepsin (SGF) or simulated intestinal fluid without pancreatin (SIF), prepared in accordance with the guidelines of the Ph. Eur. $9^{\text {th }}$ ed. and then incubated at $37^{\circ} \mathrm{C}$. The sample $(1 \mathrm{~mL})$ was collected at different time points for the determination of the average hydrodynamic diameter and polydispersity index by DLS. Each analysis was performed in triplicate in three different batches.

The in vitro release study of tacrolimus from drug-loaded NE was performed in gastric (SGF-SLS) and intestinal (FaSSIF-V2) fluids, under sink condition $\left(2 \mu \mathrm{g} \cdot \mathrm{mL}^{-1}\right.$ tacrolimus concentration), using the dialysis method. A dialysis bag (Spectrum ${ }^{\mathrm{TM}}$ Spectra/Por ${ }^{\mathrm{TM}}$ dialysis membrane, MWCO: 6-8 kDa, Fisher Scientific, Illkirch, France) containing $400 \mu \mathrm{L}$ of loaded NE $\left(1.0 \mathrm{mg} \cdot \mathrm{mL}^{-1}\right)$ was placed in $200 \mathrm{~mL}$ of release medium and incubated at $37{ }^{\circ} \mathrm{C}$ under a stirring rate of $150 \mathrm{rpm}$. Tacrolimus-loaded NE were withdrawn from dialysis bags at predetermined time intervals (up to $8 \mathrm{~h}$ in SGF and up to $72 \mathrm{~h}$ in FaSSIF-V2) and total tacrolimus content was determined by HPLC. In the case of release into FaSSIF$\mathrm{V} 2$, analysis was also performed at $50^{\circ} \mathrm{C}$, which is above $\mathrm{S} 1$ excipient melting point $\left(43^{\circ} \mathrm{C}-48^{\circ} \mathrm{C}\right)$. Tacrolimus dissolved in a mixture of ethanol and water (30:70) at $1 \mathrm{mg} \cdot \mathrm{mL}^{-1}$ was used as control. 


\section{II.2.6. Drying techniques}

\section{II.2.6.1. Spray-drying of nanoemulsions}

The spray-drying technique was used to dry blank NE mixed with Maltodextrin (MD). Concentrations of maltodextrin of $5,7.5$ and $10 \% \mathrm{w} / \mathrm{w}$ and concentration of nanoemulsion of 5,10 and $15 \% \mathrm{w} / \mathrm{w}$ were investigated. Prior to spray-drying, the compatibility of blank NE with MD solutions was examined visually for checking against possible phase separation, both at room temperature and under centrifugation acceleration of $2300 \mathrm{~g}$ for $5 \mathrm{~min}$. Rheological measurements for the NE/excipients suspensions were performed using a MCR 302 rheometer (Anton Paar, Les Ulis, France) at controlled temperature $\left(20 \pm 2{ }^{\circ} \mathrm{C}\right)$. Then, $50 \mathrm{~g}$ of mixture of NE and MD were spray-dried with a Mini Spray-dryer Büchi B191 (Büchi, Rungis, France) (NAM: Flawil, Switzerland), which had a two-fluid nozzle with cap-orifice diameter of $0.7 \mathrm{~mm}$ and operated in a co-current mode. The applied process parameters were: inlet temperature $=120^{\circ} \mathrm{C}$, aspirator setting $=50 \%$ of the maximum capacity, pump rate $=3 \mathrm{~mL} / \mathrm{min}$. The spray-dried powder was recovered and kept in closed vials (room temperature) to avoid moisture sorption.

\section{II.2.6.2. Freeze-drying of nanoemulsions}

NE was freeze-dried without or with trehalose (TR) as a cryoprotectant. Concentrations of trehalose of $1,2.5,5$ and $10 \% \mathrm{w} / \mathrm{w}$ and concentration of nanoemulsion of $3.4,6.8,13.5$ and $27 \% \mathrm{w} / \mathrm{w}$ were investigated. Samples $(2 \mathrm{~mL})$ were transferred into $6 \mathrm{~mL}$ volume glass vials and the lyophilization was carried out in a Cryonext pilot freeze-dryer (Cryonext, Saint-Aunès, France). The freeze-drying technology was as follow: freezing at $-50^{\circ} \mathrm{C}$ for $6 \mathrm{~h}$ in the freeze-dryer chamber; primary drying from $-50^{\circ} \mathrm{C}$ to $0{ }^{\circ} \mathrm{C}$ in $24 \mathrm{~h}$; secondary drying at $20^{\circ} \mathrm{C}$ for $12 \mathrm{~h}$. Finally, the vials were sealed with rubber caps and stored at $4{ }^{\circ} \mathrm{C}$ until further analysis.

\section{II.2.6.3. Dried nanoemulsion physicochemical and morphological characterization and reconstitution}

Residual moisture content was determined by thermogravimetric analysis (TGA) using a TG 209 F1 Libra thermogravimetric analyser (Netzsch, Selb, Germany) at a heating rate of $10^{\circ} \mathrm{C} \cdot \mathrm{min}^{-1}$ and temperature range from $20^{\circ} \mathrm{C}$ to $150^{\circ} \mathrm{C}$. Following freeze-drying, the dry powders were re-hydrated by progressive addition of milli-Q water. The reconstitution time was evaluated and particle size and polydispersity index (Pdl) were measured by DLS. The morphological analysis of freeze-dried NE was performed by transmission electronic microscopy (TEM). Spray-dried NE were examined by scanning electron microscopy (SEM). The impact of drying on the loaded NE $\left(2 \mathrm{mg} \cdot \mathrm{mL}^{-1}\right)$ was determined by HPLC. The drug content and the encapsulation efficiency were measured before and after the freezedrying in order to detect any leakage during the process.

\section{II.2.7. Statistical analysis}

All data were expressed as mean \pm SD. For NE mixture design, data were statistically analysed by multiple linear regression calculations, analysis of variance (ANOVA) and residual analysis with 
Modde ${ }^{\circledR}$ software (Umetrics, Sartorius-Stedim, Sweden). A P-value lower than 0.05 was considered as indicating statistically significance.

\section{II.3. Results and discussion}

\section{II.3.1. Design and development of nanoemulsion}

NE were prepared using the emulsion phase inversion (EPI) technique and homogenization process (using a rotor-stator disperser). The principle of EPI technique is based on the catastrophic phase inversion that occurs when water is titrated over the organic phase constituted by the mixture of oil and surfactants. In our case the organic phase was made of medium chain caprylic/capric triglycerides (MCT) stabilized by a mixture of non-ionic hydrophilic and hydrophobic surfactants, polyoxyethylene(40) stearate (S1) (HLB 16.9) and oleoyl polyoxyl-6 glycerides (S2) (HLB 4). The hydrophilic surfactant, S1, was chosen among PEGylated stearates to form a steric barrier against droplet coalescence and allow formation of small particle size [12]. S2 was used as hydrophobic surfactant [21]. The selected NE components are common lipid ingredients available in the market, approved by FDA for the oral route. Worthy of mention is that for the first time they were combined in this study to create a delivery system in the nanometric range. The emulsion phase inversion region for the $\mathrm{O} / \mathrm{W}$ to $\mathrm{W} / \mathrm{O}$ transition was studied in selected NE prepared by adding the aqueous phase to the oil phase (Fig. 1).

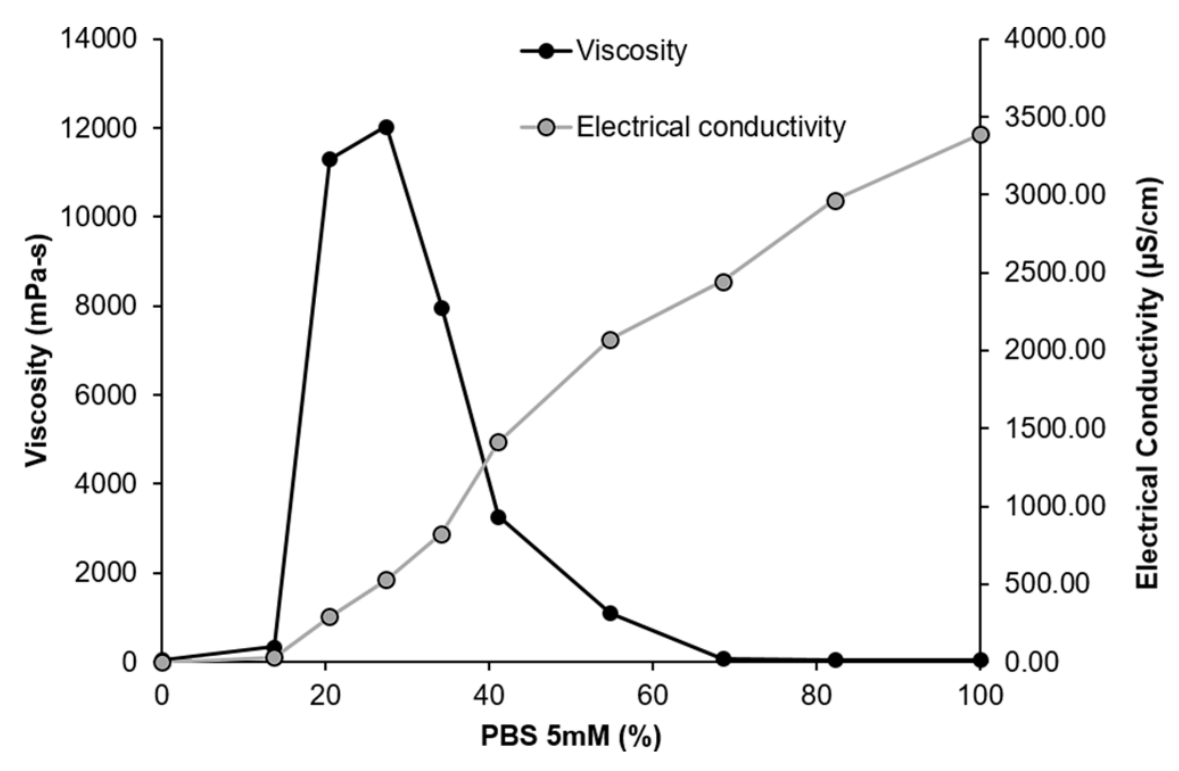

Fig. 1 Effect of water titration (phosphate buffer $5 \mathrm{mM}, \mathrm{pH}$ 7.4) on the viscosity (black line) and electrical conductivity (grey line) of $\mathrm{NE}$ at $80^{\circ} \mathrm{C}$.

The oil phase had a transparent appearance, a low electrical conductivity $\left(0.39 \mu \mathrm{S} \cdot \mathrm{cm}^{-1}\right)$ and a relatively low shear viscosity (52 $\mathrm{mPa} \cdot \mathrm{s})$. After the first water addition (14\%), the formulation became turbid. Then the addition of more water (20\%) led to formation of a milky suspension that quickly turned into a viscous gel. At this point the electrical conductivity slightly increased and the viscosity increased steeply, reaching its maximum value (12000 $\mathrm{mPa} \cdot \mathrm{s})$ at a water content of $28 \%$. The 
increase in conductivity was less pronounced (from 30 to $800 \mu \mathrm{S} \cdot \mathrm{cm}^{-1}$ ) in the range of maximum viscosity value, supporting the formation of an intermediate gel-like material. Then, when more water was added (> 28\%), the viscosity strongly decreased (3200 $\mathrm{mPa} \cdot \mathrm{s})$, the conductivity increased (up to $3000 \mu \mathrm{S} \cdot \mathrm{cm}^{-1}$ ) and the formulation presented the milky white aspect typical of O/W emulsions [13]. The intermediate highly viscous gel might be a multiple emulsion (W/O/W). At this stage, additional water made the catastrophic phase inversion to take place (W/O/W to $\mathrm{O} / \mathrm{W})$ when the small internal water droplets coalesced at the external surface of the double emulsion. The formation of a highly viscous double emulsion during formulation of NE using EPI method has previously been described $[14,35]$.

\section{II.3.2. Influence of formulation: ternary diagram and mixture design}

An exhaustive study on the influence of NE composition and method of preparation on NE physicochemical properties, drug loading, structure and stability was developed. The design of the NE formulation was carried out using ternary phase diagrams. 

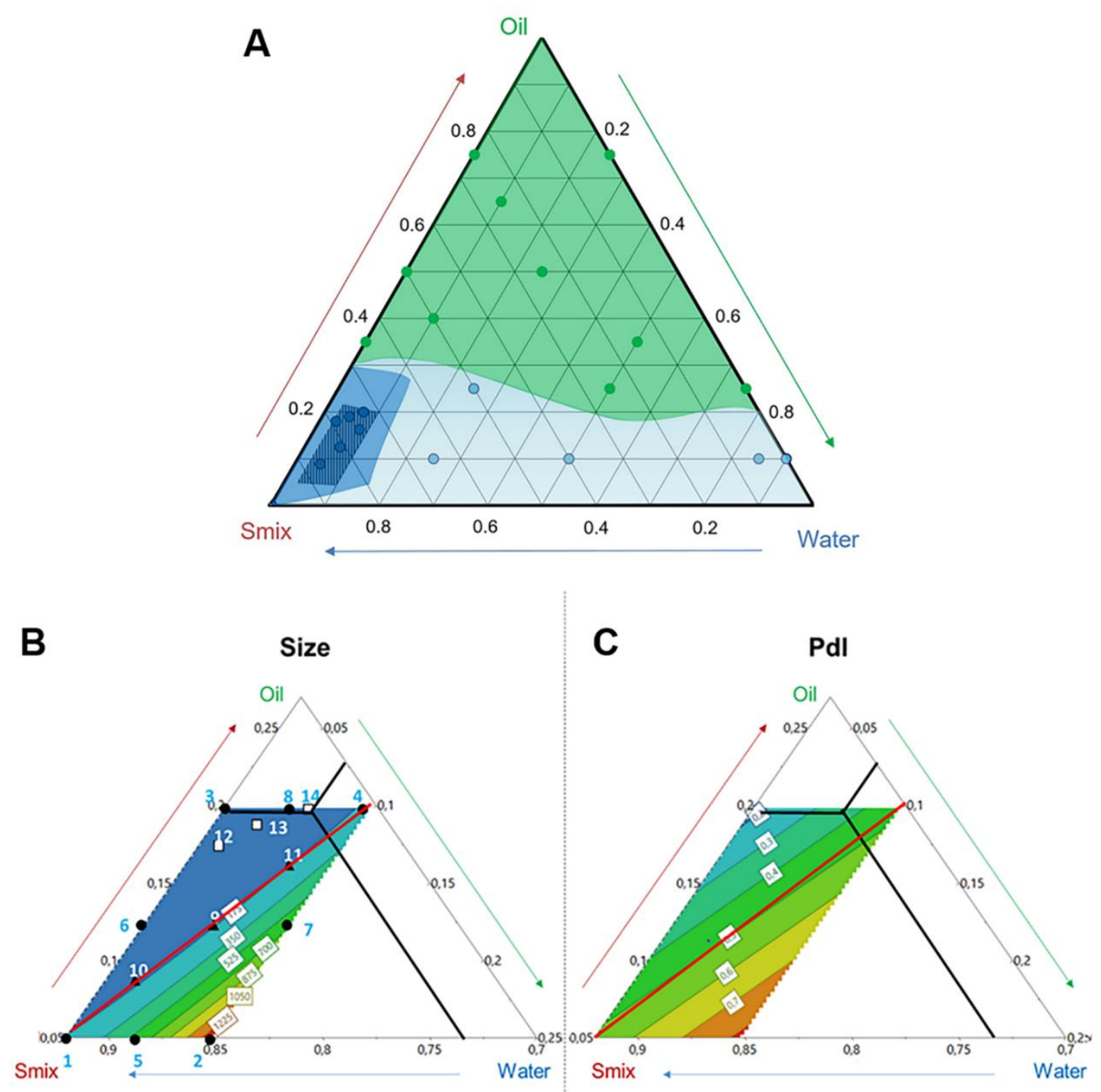

Fig. 2 A) Ternary phase diagram at $S M R=2.5$. The green area corresponds to formulations in the solid state, the two blue areas to formulations in the liquid state. The dark blue region corresponds to formulations containing NE. The trapezoid-shaped area is the selected reduced region of interest (ROI) for refined analysis. $B$ and C) Pseudoternary phase diagram at $S M R=2.5$. Contour plots of the predicted droplet mean size (B) and Pdl (C) in the triangle defined by the lower bounds of mass fractions of oil, water and Smix (SMR=2.5) with design points $(\bullet)$, check points $(\boldsymbol{\Delta})$ and optimized formulations ( $\square$ ). The composition of the selected optimized formulation (formulation number 14) is indicated by black lines. The red line corresponds to $S O R=2$.

The apices of the phase diagram were oil (MCT), water and surfactant mixture (Smix). Three different Smix compositions (1, 2.5 and 5) were studied (data can be found in the Supplementary Information file). For all diagrams, three domains were identified: solid state, liquid-gel state, and liquid state in which the domain of interest for NE formation was found. The area of the solid state domain increased with respect to SMR (from 1 to 5), which was attributed to the high content of S1. High 
viscosity is related to the large amount of hydrophilic PEG chains swollen by water via hydrogen bonding. This effect was correlated with an increase in the liquid-gel state formation observed at $S M R$ of 2.5 and 1. A NE domain was present for all SMR. It was attained when the water content ranged from 0.7 to 0.95 , the oil ranged from 0.02 to 0.15 and Smix ranged from 0.02 to 0.30 . At $S M R$ $=5$ the NE area was smaller than at $S M R=1$ and 2.5 and NE were highly viscous, which made the formation of NE more difficult $[8,23]$. At $S M R=1$ and 2.5, the extent of the NE area was higher; it was the largest at $S M R=2.5$.

The system at $S M R=2.5$ was selected for optimization purpose (Fig. 2). Thus, the relation between the organic phase composition and the size characteristics of the resulting NE was more in-depth investigated by means of an experimental design in a pseudo-ternary phase diagram. Upper and lower bounds on the proportions of the NE components were defined according to the ternary phase diagram results (trapezoid-shaped area in Fig. 2A). The resulting set of constraints on the component mass fractions was: $0.03<x_{\text {oil }}<0.1,0.05<x_{\text {Smix }}<0.2$ and $0.7<x_{\text {water }}<0.92$. The constrained experimental domain consisting of four vertices and four edges is shown in Fig. 2A. It is represented in the triangle whose vertices were obtained from the lower bounds of the NE components.

The eight design points corresponding to the 4 extreme vertices and the midpoints of the four edges of the constrained region (runs 1 to 8 in Table 1) were chosen in order to fit the second-degree Scheffé polynomial:

$\mathrm{Y}=\sum_{i=1}^{3} b_{i} x_{i}+\sum \sum_{i<j}^{3} b_{i j} x_{i} x_{j}$

Eq. 6

According to Scheffé [22], the vertices of the experimental domain are the most useful points for estimating the coefficients of the linear blending terms $b_{i}$, while the midpoints of the edges are better useful for estimating the binary blending parameters $b_{i j}[22,23]$. The overall centroid of the constrained experimental domain (run 9) was used as a validation point to check the predictive performance of the developed model (Table 1). 
Table 1 Mixture design and size distribution results.

\begin{tabular}{llllllll}
\hline Run & & $\boldsymbol{x}_{\text {oil }}$ & $\boldsymbol{X}_{\text {Smix }}$ & $\boldsymbol{x}_{\text {water }}$ & $\boldsymbol{S O R}$ & $\boldsymbol{d}(\mathbf{n m})$ & Pdl \\
\hline $\mathbf{1}$ & Design Point (vertex) & 0.030 & 0.050 & 0.920 & 1.7 & 193 & 0.51 \\
$\mathbf{2}$ & Design Point (vertex) & 0.100 & 0.050 & 0.850 & 0.5 & 1500 & 0.82 \\
$\mathbf{3}$ & Design Point (vertex) & 0.030 & 0.200 & 0.770 & 6.7 & 108 & 0.27 \\
$\mathbf{4}$ & Design Point (vertex) & 0.100 & 0.200 & 0.700 & 2.0 & 245 & 0.42 \\
$\mathbf{5}$ & Design Point (edge midpoint) & 0.065 & 0.050 & 0.885 & 0.8 & 507 & 0.66 \\
$\mathbf{6}$ & Design Point (edge midpoint) & 0.030 & 0.125 & 0.845 & 4.2 & 124 & 0.30 \\
$\mathbf{7}$ & Design Point (edge midpoint) & 0.100 & 0.125 & 0.775 & 1.3 & 596 & 0.77 \\
$\mathbf{8}$ & Design Point (edge midpoint) & 0.065 & 0.200 & 0.735 & 3.1 & 141 & 0.23 \\
$\mathbf{9}$ & Check point (centroid) & 0.065 & 0.125 & 0.810 & 1.9 & 199 & 0.58 \\
$\mathbf{1 0}$ & Check point & 0.048 & 0.088 & 0.865 & 1.8 & 182 & 0.42 \\
$\mathbf{1 1}$ & Check point & 0.083 & 0.163 & 0.755 & 2.0 & 185 & 0.43 \\
$\mathbf{1 2}$ & Optimized formulation & 0.030 & 0.180 & 0.790 & 6.0 & 107 & 0.30 \\
$\mathbf{1 3}$ & Optimized formulation & 0.050 & 0.190 & 0.760 & 3.8 & 131 & 0.25 \\
$\mathbf{1 4}$ & Optimized formulation & 0.070 & 0.200 & 0.730 & 2.9 & 137 & 0.20 \\
\hline
\end{tabular}

The results (Table 1 ) showed very large variations of NE size distribution with a mean size ranging from about 100 to $1500 \mathrm{~nm}$ and Pdl comprised between 0.23 and 0.82 . The eight first experiments were used to determine the regression model coefficients in Equation 6. Only the regression coefficients significant at the $5 \%$ level ( $t$-test) were kept in the model. The ANOVA results indicated the high significance of the developed model $(p<0.05)$. The determination coefficients $\left(R^{2}\right.$ and $R^{2}$ adjusted) above 0.9 also proved the satisfactory adequacy of the model. Moreover, runs 9,10 and 11 were used as a check points to evaluate the model-predictive performance: as example, the estimated mean size and Pdl for run 9 were $173 \mathrm{~nm}$ and 0.48 respectively, which were similar to the experimental values (199 $\mathrm{nm}$ and 0.58 ) indicating adequacy of model.

The estimated surface contours for the mean size (Fig. 2B) and Pdl were plotted in pseudoternary phase diagrams (Fig. 2C). The region of interest corresponding to a mean diameter less than $140 \mathrm{~nm}$ is coloured in dark blue in Fig. 2B. The area where $\mathrm{Pdl}<0.3$ (Fig. 2C) was larger than that where $D<$ $140 \mathrm{~nm}$, so that the whole dark blue region of Fig. 2A corresponded to satisfactory formulations with regards to the Pdl criterion. The amounts of Smix and oil in the formulations greatly influenced both the mean size and Pdl. As expected, low Pdl's were obtained at large $x_{\text {Smix }}$ and low $x_{\text {oil }}$ and small droplet mean diameters required $x_{\text {oil }}$ less than 0.08 . From these results, three optimized formulations were identified on the basis of two selection criteria: i) stability, ii) high oil content: runs 12,13 and 14. The optimized NE that had maximum oil content was run 14 (indicated by black lines in Fig. 2B and $2 \mathrm{C}$ ); its composition contained oil, Smix and water mass fractions of $0.07,0.2$ and 0.73 , respectively.

Besides, the surfactant-to-oil ratio $(S O R)$ was studied for $S M R=2.5$. Nanometric droplets smaller than $200 \mathrm{~nm}$ were formed at $S O R \geq 2$. High surfactant concentrations allowed the formation of 
smallest droplets. However, at the highest surfactant concentrations tested (SOR=6), a bimodal particle size distribution was observed.

The stability of formulations was estimated using homogeneity and size measurements as readouts. After 4 days of storage at $20^{\circ} \mathrm{C}$, stable and monodispersed NE $(\mathrm{Pdl}<0.2)$ were obtained at $S M R=2.5$ and $S O R=2.86,4.04$ and 5. The results confirmed the interdependency between SOR and overall surfactant amount in NE. In fact, stability was achieved when there was a sufficient surfactant amount to cover droplet surfaces [24].

Overall, the goal of developing a stable NE, maximizing the oil content (7\%), was achieved by setting $S M R=2.5$ (HLB 13.2) and SOR $=2.86$ (Fig. 2B and 2C). The use of an experimental design provided a rigorous methodology for optimization of formulation, which is much more suitable than the "classical" method based on trial-and-error. The full region of interest, expressed in terms of practical formulation parameters such as $S M R, x_{\text {oil }}$ and $S O R$, was disclosed. Then, the optimum formulation with regards to stability, size and polydispersity criteria was selected by a minimum number of experiments.

Previous studies demonstrated that the development, physicochemical attributes and stability of NE may be improved by using associations of two or more different emulsifiers, rather than an individual type [25]. TEM observations of emulsions prepared with S1 alone showed that droplets exhibited a clear tendency to aggregate (images can be found in the supplementary section). Thus, the presence of a hydrophobic surfactant $(S 2)$ in $\operatorname{Smix}(S M R=2.5, S O R=2.86)$ was mandatory for ensuring stability.

The Smix that yielded stable NE had a hydrophilic-lipophilic balance (HLB) close to the required HLB of the oil phase (13.2) [26]. The HLB values of the surfactant mixture were 10.5, 13.2 and 14.3 at SMR $=1,2.5$ and 5, respectively. Based on this assumption, the NE at $S M R=2.5$ matched the required $\mathrm{HLB}$ of MCT.

The stability of NE in colloidal suspension was assessed at $20{ }^{\circ} \mathrm{C}$ and $37{ }^{\circ} \mathrm{C}$, over 28 days (supplementary materials). No creaming or sample degradation were observed during the studied period and the mean size and polydispersity index ( $\mathrm{Pdl}$ ) measured by DLS remained stable.

The robustness of the formulation process was evaluated by scaling up the NE. A batch 10 times bigger than the optimized one was produced. NE (scaled $\times 10$ ) maintained their initial physicochemical properties in terms of size and polydispersity (data not shown), indicating that the process can be transposed to a larger scale production.

\section{II.3.3. Physicochemical and morphological characterization of optimized nanoemulsions}

Optimized NE had mean droplet size of around $104 \pm 3 \mathrm{~nm}$, a low Pdl (0.2) and a neutral/slightly negative $\zeta$-potential $(-9 \pm 1 \mathrm{mV})$. This neutral surface charge derived from the PEGylated surfactant (S1) shell hinders interactions with intestinal contents and mucus layer, thus enhancing NE diffusion to the epithelium and translocation through the mucosa [52].

Transmission electron microscopy (TEM) and Cryo-TEM observations (Fig. 3A to 3D) were performed to study their morphology. TEM images showed a monodispersed population of spherical droplets with a smooth surface. However, to perform TEM observations, samples were dried on the grid and 
the interaction of NE with the electron beam may cause structural alteration of particles, leading to a misinterpretation of results. Cryo-TEM was thus performed to directly investigate NE in the frozenhydrated state, very close to their native state [27]. Moreover, Cryo-TEM observation allows the discrimination of smaller and bigger particles. Finally, it confirmed that NE formulations presented quite monodispersed population of spherical droplets.
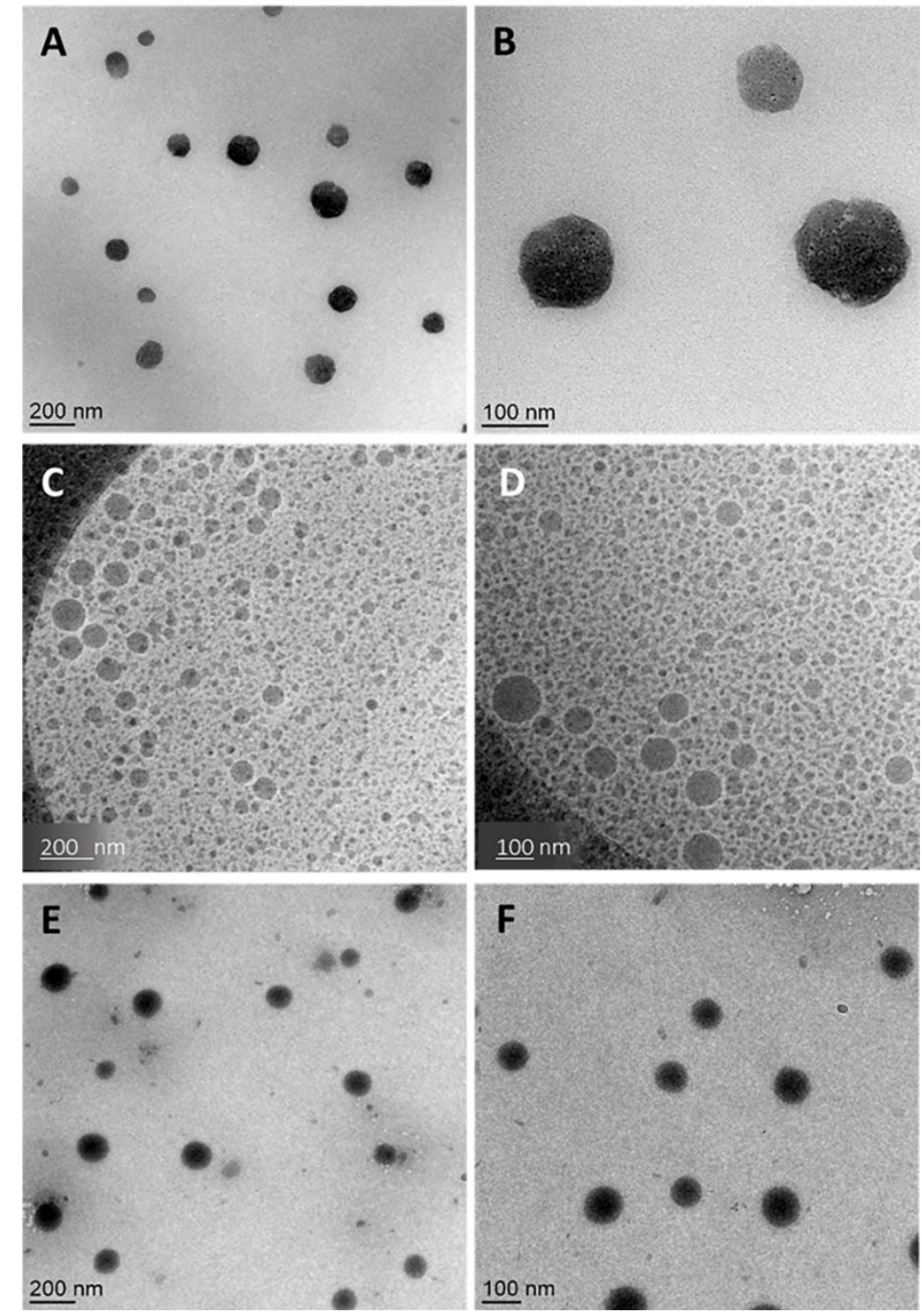

Fig. 3 A and B) TEM of blank NE, C and D) Cryo-TEM of blank NE, E and F) Cold TEM of tacrolimusloaded NE. All images are at magnification of $200 \mathrm{~nm}$ and $100 \mathrm{~nm}$.

\section{II.3.4. Tacrolimus-loaded nanoemulsion formulation and physicochemical characterization}

Tacrolimus, an immunomodulatory agent used in the treatment of various diseases [19], was encapsulated into the NE as hydrophobic model drug. The fundamental prerequisite to obtain a high encapsulation efficiency of the drug in nanosystems is a high solubility of the active compound in excipients. The solubility of tacrolimus was $11.9 \pm 0.01 \mathrm{mg} \cdot \mathrm{mL}^{-1}$ in $\mathrm{MCT}, 29.9 \pm 0.003 \mathrm{mg} \cdot \mathrm{mL}^{-1}$ in S2 and $30.6 \pm 0.01 \mathrm{mg} \cdot \mathrm{mL}^{-1}$ in S1, suggesting the feasible encapsulation of the drug in NE.

Thus, tacrolimus was mixed with the NE oil phase $\left(2 \mathrm{mg} \cdot \mathrm{mL}^{-1}, S M R=2.5, S O R=2.86\right)$ by magnetic stirring $(750 \mathrm{rpm})$ at $80^{\circ} \mathrm{C}$ for $2 \mathrm{~h}$ to reach equilibrium, and NE were prepared performing two cycles 
of 10 min stirring at $80{ }^{\circ} \mathrm{C}$. Physicochemical characteristics of tacrolimus-loaded NE and blank NE were the same: mean diameter was $96 \mathrm{~nm}$ against $104 \mathrm{~nm}$, Pdl was 0.23 vs 0.22 and 弓-potential was $-8.7 \mathrm{mV}$ vs $-9.1 \mathrm{mV}$. Moreover, owing to the high lipophilic character of tacrolimus, encapsulation efficiency was close to $100 \%$ ( $99.5 \%$ was measured), with a drug loading of around $0.74 \%$. This encapsulation efficiency is higher than for tacrolimus-loaded ethosomes (around 80\%) [28] and lipid nanocapsules (over 90\%) [29]. Moreover, the drug content $\left(2 \mathrm{mg} \cdot \mathrm{mL}^{-1}\right)$ was higher when compared to lipid system previously developed for the oral delivery of tacrolimus $\left(0.79 \pm 0.05 \mathrm{mg} \cdot \mathrm{mL}^{-1}\right.$ in lipid-core nanocapsules [53]) highlighting the interest of exploiting such formulation to further enhance drug deliver across the oral absorption barrier. DLS measurements were confirmed by "cold TEM" observations (Fig. 3E and 3F). After preparing TEM grids and let sample dry overnight, TEM grids were frozen in liquid ethane and observed by Cryo-TEM. Cold TEM images showed that loaded NE formed monodispersed population with a spherical shape.

The stability of loaded NE in colloidal suspension, upon storage at both at $20^{\circ} \mathrm{C}$ and $37{ }^{\circ} \mathrm{C}$, was followed over 28 days (supplementary materials). Three parameters were assessed at different time points: i) macroscopic aspect (presence of aggregates, cream formation or changes in colour); ii) particle size, polydispersity and $\zeta-$ potential; and iii) tacrolimus concentration in the preparation and leakage of the drug. No sample degradation was observed and mean size, polydispersity index (PdI) and surface potential remained stable during the studied period. Moreover, $75 \%$ of encapsulated tacrolimus was retained in the NE upon 28 days of storage at $20^{\circ} \mathrm{C}$.

\section{II.3.5. Stability and in vitro release of tacrolimus-loaded nanoemulsion in simulated GI fluids}

The stability of loaded NE in terms of size evolution was assessed upon incubation during $3 \mathrm{~h}$ in SGF and $8 \mathrm{~h}$ in SIF media (data presented in the supplementary materials). Results indicated that loaded NE maintained their initial size in the experimental conditions tested.

Release behaviour of loaded NE was evaluated in vitro under sink conditions in SLS-SGF and in FaSSIFV2 (Fig. 4). Tacrolimus dissolved in a mixture of ethanol and water (30:70) was used as a control. 


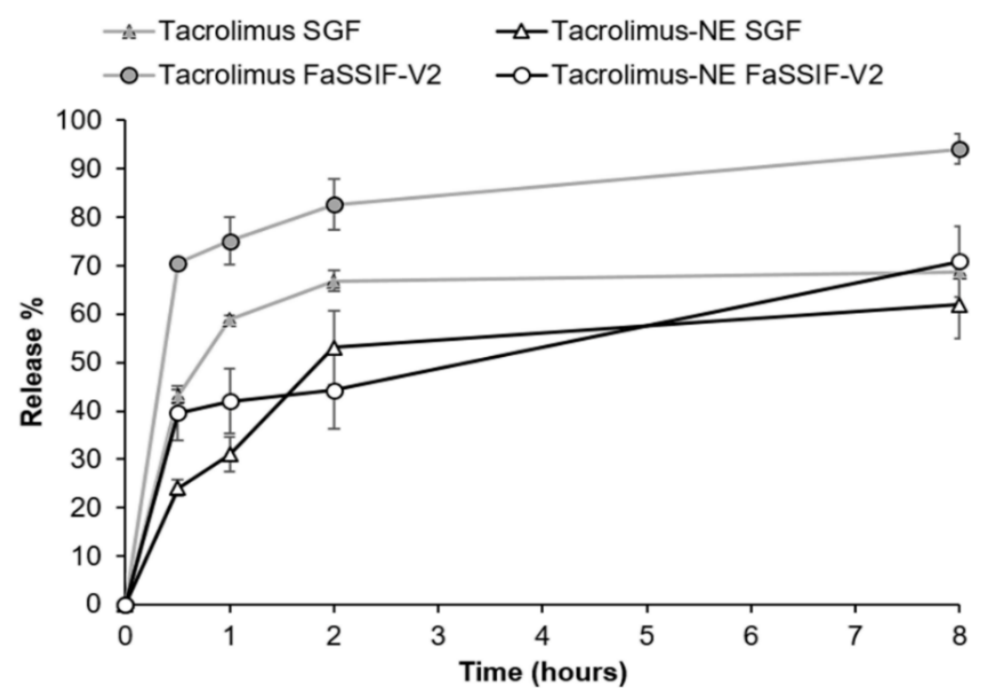

Fig. 4 In vitro release profiles of tacrolimus from ethanol/water solution and loaded NE in SGF (pH 1.2) or FaSSIF-V2 ( $\mathrm{pH}$ 6.5). Mean $\pm \mathrm{SD}, \mathrm{n}=3$. SGF: simulated gastric fluid in presence of sodium lauryl sulfate (SLS $0.5 \% \mathrm{w} / \mathrm{v})$; FaSSIF-V2: simulated intestinal fluid in fasted state. 
Upon $30 \mathrm{~min}$ of incubation in SLS-SGF, 25\% of the drug was released from the NE, reaching $50 \%$ during $2 \mathrm{~h}$. Then, no further release was detected in the following $8 \mathrm{~h}$. In FaSSIF-V2, 39\% of tacrolimus was released during the first $30 \mathrm{~min}$, then, $45 \%$ until $2 \mathrm{~h}$. A plateau was reached following $10 \mathrm{~h}$ of incubation, with $75 \%$ of tacrolimus released up to $72 \mathrm{~h}$ (data shown in the supplementary section).

Controls showed that the release rate was not due to diffusion through the dialysis membrane. Tacrolimus solubilized in ethanol/water mixture was rapidly released in SGF, reaching $40 \%$ in 30 min followed by $60 \%$ of release in $8 \mathrm{~h}$. In FaSSIF-V2, the release was faster, reaching $70 \%$ in $30 \mathrm{~min}$, and $94 \%$ in $8 \mathrm{~h}$. Tacrolimus was released in a sustained manner once encapsulated in the NE compared to drug solutions. This behaviour was correlated to the high affinity of the drug with the oil core of NE, which resulted from the high hydrophobicity of tacrolimus. Overall, around $40 \%$ of drug would be available upon $1 \mathrm{~h}$ of oral administration and the complement would be released within $24 \mathrm{~h}$ in a controlled sustained manner, thereby acting as maintenance dose. In accordance with previous studies, this profile might be beneficial to overcome fluctuations in drug plasma levels [54].

\section{II.3.6. Conversion into dry solid powders}

To increase the stability of the system both spray-drying and freeze-drying techniques were exploited. The drying of nanosystems allows to overcome limitations of conventional (liquid) formulations (as storage instability, particle aggregation, drug leakage and microorganism growth over time [30]) and favor the oral administration of dry NE in a powder form (i.e. capsules, Tablets). Spray-drying is a single step procedure for drying liquid formulations by rapid water evaporation in a hot gas flow [31]. While, in the case of freeze-drying, the conversion into a solid powder involves removal of water by sublimation of ice crystals from frozen material at low pressure and low temperature [32]. The use of heat is avoided, therefore making the freeze-drying the most common processing method for removing moisture from biopharmaceuticals and for producing high quality powder for thermosensitive drugs. However, freeze-drying is still challenging for the production of dry emulsions and NE due to several critical steps (cryoprotectant choice, freezing rate and conditions, primary and secondary drying process) which need to be controlled [32].

The use of drying excipients (trehalose, maltose, sucrose, glucose, maltodextrin or mannitol) is highly recommended in both processes. During the spray drying process, excipients are added to provide a matrix to the dry product while it is heated to high temperatures [31]. Using specific excipients such as lactose or maltodextrin, several dispersed systems, as emulsions, liposomes and nanocapsules, have been successfully spray-dried with preservation of their initial properties that allows reconstitution of an aqueous suspension [31]. While, in freeze-drying, cryoprotectants and lyoprotectants (i.e. trehalose, sucrose, lactose) are used to prevent the disruption of the droplets during freezing and drying steps [32]. Both spray-drying and freeze-drying technologies were evaluated with regards to obtain dry powders of NE. Firstly, the feasibility of both processes was assessed and maltodextrin (MD) and trehalose (TR) were rationally selected as drying excipients to improve spray-drying and freeze-drying performance, respectively. The dry powders were 
characterized in terms of moisture content, product yield and macroscopic properties. Then, following reconstitution by rehydration, NE physicochemical properties were assessed.

\section{II.3.6.1. Nanoemulsions spray-drying and characterization}

During the spray-drying process, the prevention of phase separation between NE and excipients before the feed pumping step is crucial to prepare homogeneous powders and to ensure effective NE protection [31,33]. In this study, NE were spray-dried in presence of maltodextrin (MD) as drying excipient based on both maltodextrin finest attributes, as from the literature [31], and on preliminary studies comparing the homogenization properties of NE with maltodextrin, lactose and hydroxypropyl methylcellulose (HPMC) (results not shown). Phase separation of NE/MD mixtures was studied at equilibrium as well as under centrifugal forces. When the MD solution was mixed with the NE at different ratios (Table 2), no spontaneous phase separation occurred in all studied samples up to $2 \mathrm{~h}$. However, after $6 \mathrm{~h}$, creaming occurred in samples whose MD concentration exceeded $7.5 \%$. Creaming was also observed after centrifugation of samples at high MD concentrations (MD > $7.5 \%)$.

Table 2 Compatibility of NE with different concentration of maltodextrin (MD) "- "No separation; " + " Light separation, with very thin upper cream layer; “+++" Obvious separation, with upper creamed layer. \% expressed as\% w/v.

\begin{tabular}{|c|c|c|c|c|c|c|}
\hline \multirow{2}{*}{$\begin{array}{l}\text { NE (\% } \\
w / v)\end{array}$} & \multirow{2}{*}{$\begin{array}{l}\text { MD (\% } \\
w / v)\end{array}$} & \multicolumn{2}{|c|}{ Equilibrium } & \multirow[b]{2}{*}{$6 \mathrm{~h}$} & \multirow{2}{*}{$\begin{array}{l}\text { Centrifugation }(2300 \mathrm{~g}, \\
5 \mathrm{~min})\end{array}$} & \multirow{2}{*}{$\begin{array}{l}\text { Viscosity at } 20^{\circ} \mathrm{C} \\
\text { (mPa.s) }\end{array}$} \\
\hline & & $15 \mathrm{~min}$ & $2 \mathrm{~h}$ & & & \\
\hline 5 & 5 & - & - & - & - & 2.1 \\
\hline 5 & 10 & - & - & - & + & 3.3 \\
\hline 10 & 5 & - & - & - & - & 3.6 \\
\hline 10 & 10 & - & + & +++ & +++ & 6.2 \\
\hline 15 & 7.5 & - & + & +++ & +++ & 8.2 \\
\hline 15 & 10 & - & + & +++ & +++ & 11.7 \\
\hline
\end{tabular}

Emulsions mixed with MD solutions show an enhance rate of creaming when a critical MD concentration, defined as critical flocculation concentration (CFC), is exceeded. Above the CFC the non-adsorbed MD molecules in the aqueous phase cause depletion flocculation of NE droplets [34]. In our experiment the critical flocculation concentration (CFC) was identified at MD concentrations $\geq$ $7.5 \%$.

Too high viscosity of the initial solution hinders homogenous atomization and correct drop formation [48]. An increase of MD and NE concentrations (from 5 to 15\%) led to a slight increase of viscosity (from 2 to $12 \mathrm{mPa} \cdot \mathrm{s}$ ). However, the overall viscosity remained low ( $<12 \mathrm{mPa} \cdot \mathrm{s}$ ) and spray-drying could be performed even at high NE concentration ( $15 \% \mathrm{w} / \mathrm{v})$. Following the spray-drying process, powders were recovered both from the cyclone wall and bottom. Macroscopic characteristics of powder obtained are presented in Table 3. 
Table 3 Characteristics of spray-dried NE powders.

\begin{tabular}{llllll}
\hline $\begin{array}{l}\text { NE (\% } \\
\mathbf{w} / \mathbf{v})\end{array}$ & $\begin{array}{l}\text { MD (\% } \\
\mathbf{w} / \mathbf{v})\end{array}$ & $\begin{array}{l}\text { Ratio } \\
\mathbf{N E} / \mathrm{MD}\end{array}$ & Macroscopic properties & $\begin{array}{l}\text { Moisture content }(\% \\
\mathbf{w} / \mathbf{v})\end{array}$ & $\begin{array}{l}\text { Yield }(\% \\
\mathbf{w} / \mathbf{v})\end{array}$ \\
\hline 5 & 5 & 1 & $\begin{array}{l}\text { White powder, good } \\
\text { flowability }\end{array}$ & 3.1 & 77.3 \\
5 & 10 & 0.5 & $\begin{array}{l}\text { White powder, good } \\
\text { flowability }\end{array}$ & 4.5 & - \\
10 & 5 & 2 & $\begin{array}{l}\text { White powder, } \\
\text { sticky }\end{array}$ & 1.7 & 89.2 \\
10 & 10 & 1 & $\begin{array}{l}\text { White powder, good } \\
\text { flowability }\end{array}$ & 3.7 & 73.2 \\
15 & 7.5 & 2 & $\begin{array}{l}\text { White powder, } \\
\text { quite sticky } \\
\text { White powder, good } \\
\text { flowability }\end{array}$ & 2.4 & 92.8 \\
\hline
\end{tabular}



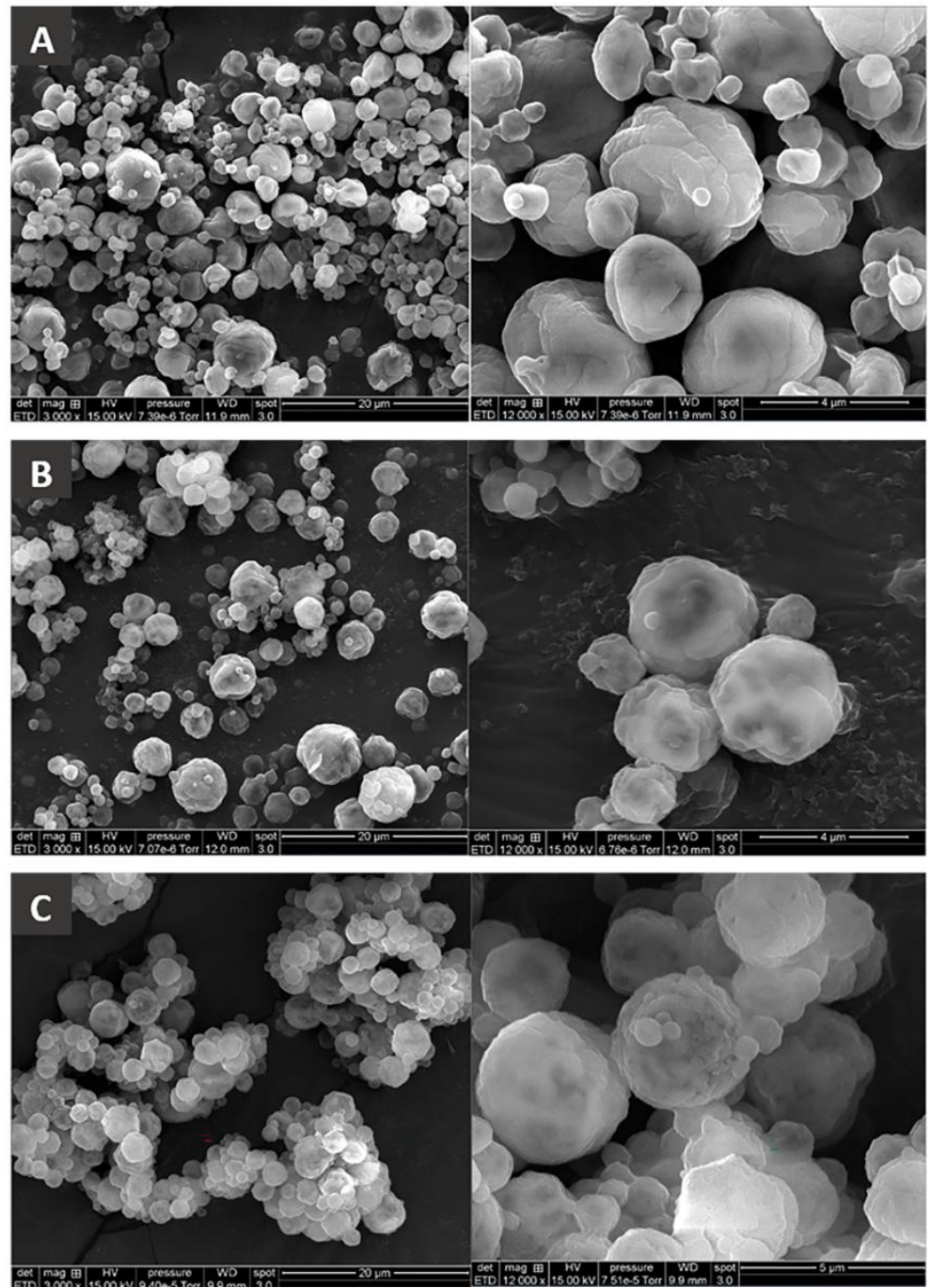

Fig. 5 SEM images of spray-dried NE at different NE and MD concentrations (\% w/v). NE:MD = A) 5:10; B) 10:10; C) 15:10.

Powders were pasty and stuck to the cyclone bottom when spray-dried with a NE/MD ratio of 2 . Formulations with lower NE/MD ratios of 1.5, 1 and 0.5 resulted in smooth powders, which could be collected at the cyclone wall. Residual moisture content of all obtained powders was very low, varying from $1.7 \%$ to $4.5 \%$ (Table 3). It is worthy to notice that two sticky powders, corresponding to formulations with an NE/MD ratio of 2 , showed the lowest value of relative humidity $(1.67 \%$ and $2.4 \%$, respectively). Their sticky state resulted from the exposure of the oil phase of droplets, due to the low amount of MD present in the powder. The sticky state of the formulation having NE-MD concentration of $10 \%-5 \%$ hampered the powder collection for further analysis. Process yields were satisfying, with values ranging from 70 to $93 \%$, for all other mixtures (Table 3). 90\% yield was reached for the mixture containing $10 \%$ of MD and NE at $5 \%$. Such yields are much higher than the ones reported in the literature. In fact, previous works reported process yields between $30 \%$ and $40 \%$ for lipid-core nanocapsules (1\%) spray-dried in presence of lactose (10\% w/v) [35]. Also, nanocapsules (1\%) were spray-dried in presence of $\mathrm{MD}(10 \% \mathrm{w} / \mathrm{v})$ and the process yield was $66.9 \%$ [31]. 
SEM observations of NE powders (Fig. 5) revealed particles with a spherical shape and a folded surface with a broad size distribution, ranging from $500 \mathrm{~nm}$ to $6 \mu \mathrm{m}$ (Fig. 5). The powders obtained for NE:MD concentrations of 5:10 (Fig. 5A) and 10:10 (B) (Fig. 5B) were composed of single particles while, in the case of powder obtained from higher NE:MD concentrations of 15:10 (Fig. 5C) particles looked like irregular agglomerates. Agglomeration was probably related to a phenomenon of interparticle adhesion during drying process, caused by the low amount of MD that did not provide an effective protective shell against sticking.

The stability after spray-drying was assessed by evaluating the ability of NE to recover their initial physicochemical properties following reconstitution in water (Fig. 6A). When NE (concentration 15$10-5 \%$ ) was spray dried in presence of $M D$ at $10 \%$, no variation in terms of NE size and Pdl were detected. While, for powders prepared using NE at 15 and $5 \%$ and MD at 7.5 and 5\% respectively, an increase of NE hydrodynamic diameter (from $102 \mathrm{~nm}$ to $260 \mathrm{~nm}$ and $225 \mathrm{~nm}$, respectively) and of Pdl (from 0.15 to 0.4 ) were observed following resuspension in water. 

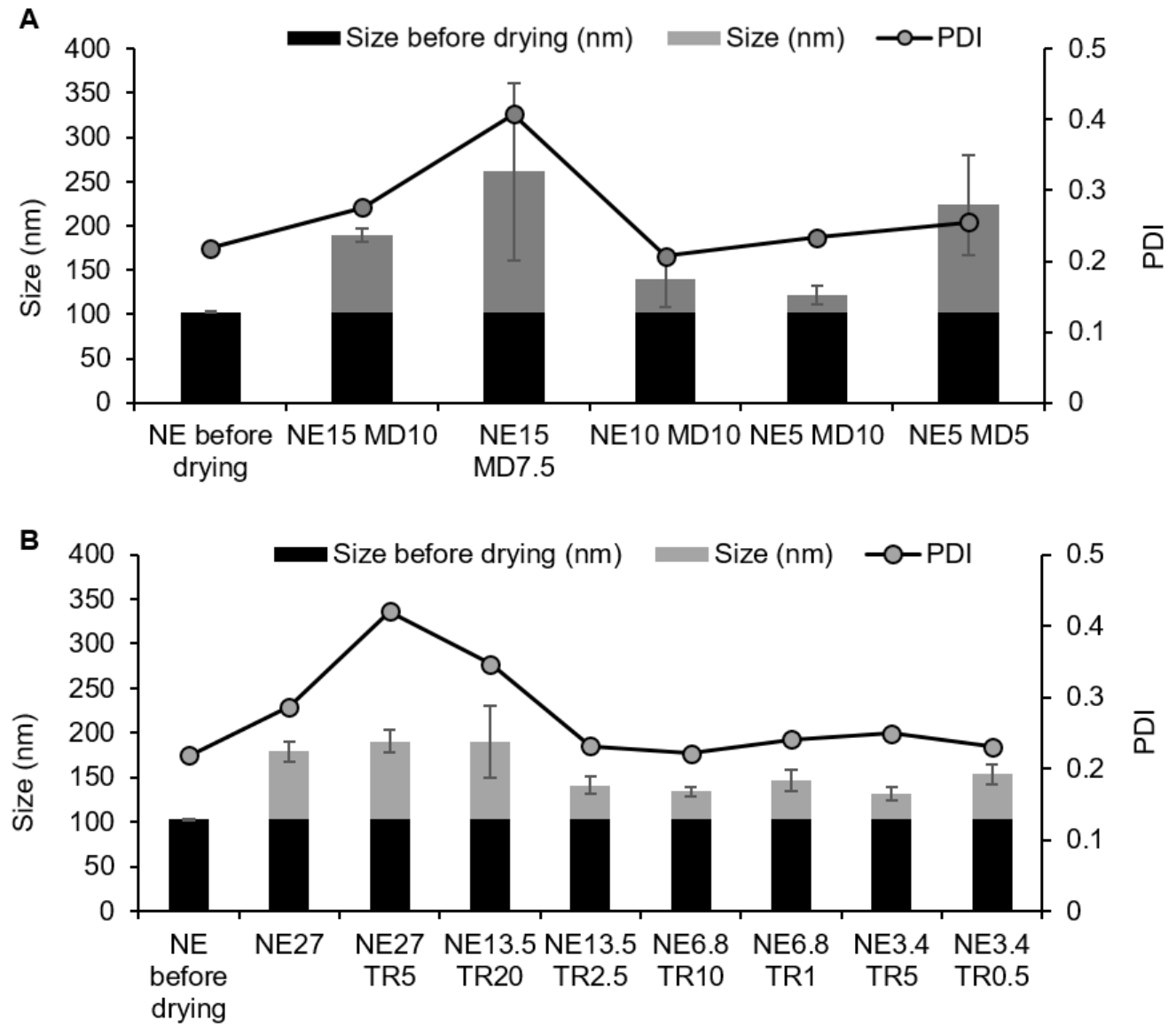

Fig. 6 Particle size and polydispersity index (PdI) of : A) re-hydrated spray-dried NE at different NE and $\mathrm{MD}$ concentrations $(\% \mathrm{w} / \mathrm{v}) ; \mathrm{B})$ re-hydrated freeze-dried $\mathrm{NE}$ at different $\mathrm{NE}$ and $\mathrm{TR}$ concentrations $(\% \mathrm{w} / \mathrm{v})$.

Overall, best results in terms of production yield, moisture content and stability following reconstitution were obtained for the mixture prepared at NE concentration of $5 \%$ and MD concentration of $10 \%$.

\section{II.3.6.2. Nanoemulsions freeze-drying and characterization}

Prior to lyophilization study, a freeze-thawing experiment was performed. The choice of trehalose as drying excipient was dictated by its reported superiority in the freeze-drying process because of its reduced hygroscopy, low chemical reactivity and high glass transition temperature [32,33]. Moreover, better maintaining of NE physicochemical properties was observed with trehalose when compared to maltodextrin (results not shown). NE was mixed with TR at different concentrations (Table 4) and the stability of mixtures was evaluated upon $24 \mathrm{~h}$ of storage at $4{ }^{\circ} \mathrm{C}$. No phase separation was observed for all NE-TR mixtures.

Samples were then frozen in the freeze-drying chamber at slow freezing rate that avoided TR trapping into ice crystals [36]. Frozen NE were thawed and their physicochemical properties were analysed by DLS. Though particle sizes of all samples slightly increased (Table 4), they remained in the acceptable nanometer range $(<200 \mathrm{~nm}$ ). Size increase was more pronounced (around $70 \mathrm{~nm}$ ) in 
samples with NE/TR ratio higher than 10. Smaller and highly monodisperse $(\mathrm{Pdl}=0.1)$ particles were obtained for NE/TR ratio $\leq 6.8$.

Table 4 Physicochemical characterization of NE mixed with trehalose (TR) at different ratio following the freeze-thawing study. NE original size $=103.9 \pm 2.7 \mathrm{~nm} ; \mathrm{Pdl}=0.20$.

\begin{tabular}{lllll}
\hline NE $(\% \mathbf{w} / \mathbf{v})$ & TR $(\% \mathbf{w} / \mathbf{v})$ & Ratio NE/TR & Size $(\mathbf{n m})$ & Pdl \\
\hline 27 & & & $146 \pm 3$ & 0.13 \\
27 & 1 & 27 & $174 \pm 5$ & 0.24 \\
& 2.5 & 10.8 & $165 \pm 2$ & 0.21 \\
& 5 & 5.4 & $128 \pm 2$ & 0.12 \\
13.5 & 1 & 13.5 & $176 \pm 3$ & 0.26 \\
& 2.5 & 5.4 & $154 \pm 2$ & 0.16 \\
6.8 & 1 & 6.8 & $151 \pm 2$ & 0.14 \\
3.4 & 10 & 0.68 & $128 \pm 1$ & 0.17 \\
& 5 & 0.68 & $111 \pm 1$ & 0.12 \\
\hline
\end{tabular}

The freeze-thawing experiment showed that the freezing stage of the lyophilization process did not affect the stability of the droplets, though this is considered as one of the most critical step. On this basis, freeze-drying was performed for the samples prepared at NE/TR ratio lower than 10.

Representative pictures of the lyophilized cakes are shown in Fig. 7. The NE lyophilized without cryoprotectant resulted in elegant cakes with no defects (Fig. 7A and Table 5). White snow-like, smooth and elegant cakes were obtained for samples prepared at NE concentration of $13.5 \%$ and 2.5\% of TR (Fig. 7B). While, at low NE content (3.4\%) (Fig. 7D and Table 5) cakes resulted of poorest quality, with partial shrinkage and cracks.

Table 5 Characteristics of freeze-dried NE powders.

\begin{tabular}{|c|c|c|c|c|c|}
\hline $\begin{array}{l}\text { NE (\% } \\
w / v)\end{array}$ & $\begin{array}{l}\text { TR (\% } \\
w / v)\end{array}$ & $\begin{array}{l}\text { Ratio } \\
\text { NE/TR }\end{array}$ & Macroscopic properties & $\begin{array}{l}\text { Moisture content } \\
(\% \mathrm{w} / \mathrm{v})\end{array}$ & $\begin{array}{l}\text { Yield (\% } \\
w / v)\end{array}$ \\
\hline 27.0 & & & $\begin{array}{l}\text { White snow like smooth oily } \\
\text { cake }\end{array}$ & 0.3 & 103.6 \\
\hline 27.0 & 5 & 5.4 & $\begin{array}{l}\text { White snow like smooth } \\
\text { elegant cake }\end{array}$ & 1.2 & 97.2 \\
\hline 13.5 & 2.5 & 5.4 & $\begin{array}{l}\text { White snow like smooth } \\
\text { elegant cake }\end{array}$ & 0.9 & 99.2 \\
\hline 13.5 & 20 & 0.7 & $\begin{array}{l}\text { White snow like smooth } \\
\text { elegant cake }\end{array}$ & 2.9 & 97.5 \\
\hline 6.8 & 1 & 6.8 & White brittle cake & 0.9 & 97.9 \\
\hline 6.8 & 10 & 0.7 & White brittle cake & 3.4 & 86.5 \\
\hline 3.4 & 0.5 & 6.8 & White brittle cake, shrinkage & 0.4 & 97.8 \\
\hline 3.4 & 5 & 0.7 & White brittle cake & 3.3 & 90.0 \\
\hline
\end{tabular}




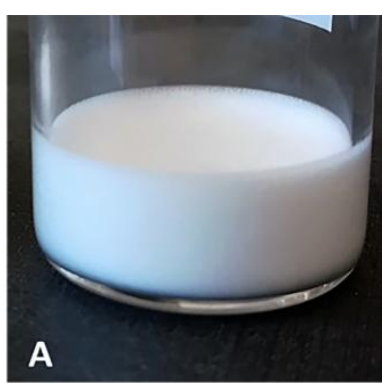

A

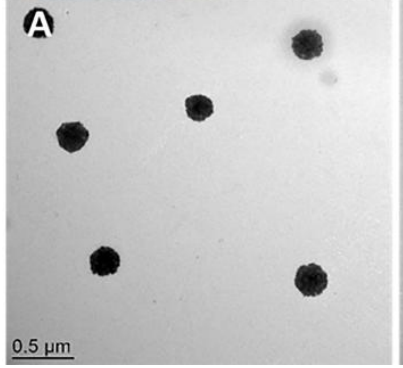

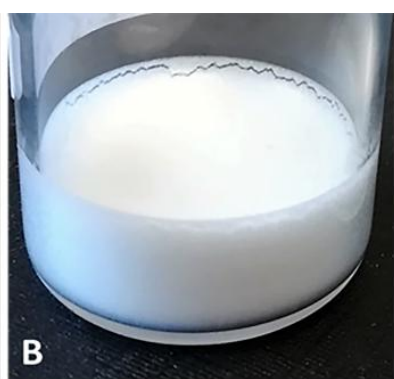

B
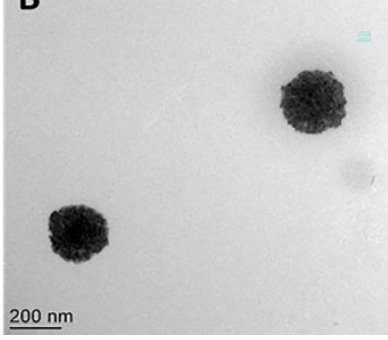
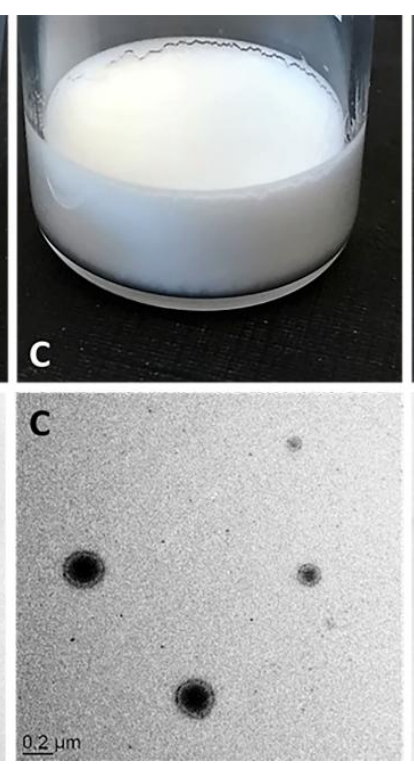

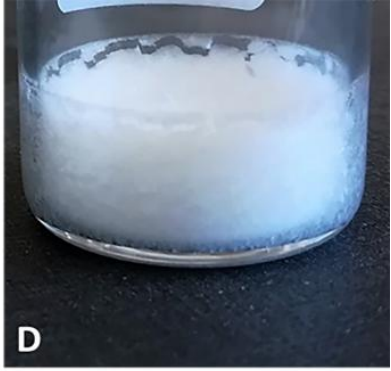

D

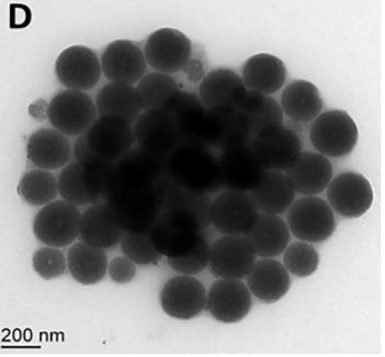

Fig. 7 Visual appearance of NE cakes and TEM images of NE after lyophilization and reconstitution in water. A) Blank NE without cryoprotectant; B) Blank-NE:TR=13.5:2.5; C) Tacrolimus-loaded $\mathrm{NE}: T R=13.5: 2.5 ; \mathrm{D})$ Blank NE:TR=3.4:5.

The residual moisture content of all obtained powders was low, varying from $0.3 \%$ to $3.3 \%$ (Table 5). The highest TR concentration tested $(10 \%, 20 \%)$ contained more moisture $(>3 \%)$. This was due to unfrozen water remaining trapped in the sugar matrix during the sublimation step. Process yields were satisfactory, with values ranging from $87 \%$ (NE:TR $=6.8 \%: 10 \%$ ) to $100 \%$ (NE 27\%) (Table 5).

The ability of dried NE to recover their initial physicochemical properties upon reconstitution in water was also evaluated. All the dried samples were rehydrated with pure water under gentle shaking and analysed for droplet size by DLS (Fig. 6B). NE without cryoprotectant (27\%) showed acceptable increase in size (from $103 \mathrm{~nm}$ to $173 \mathrm{~nm}$ ) and Pdl (0.3). However, their rehydration was difficult and slow (> $10 \mathrm{~min}$ ). NE at different concentrations were mixed with TR solutions or with the powder of TR before drying. When TR solutions (13.5\% and $6.8 \%$ ) were mixed with NE, the lyophilized cakes were easily and rapidly rehydrated (less than $1 \mathrm{~min}$ ). Physicochemical properties of $\mathrm{NE}$ at $13.5 \%$ (size $=141 \mathrm{~nm}, \mathrm{Pdl}=0.2$ ) were better preserved at TR amount of $2.5 \%$ (Fig. 6B). TEM observations (Fig. 7B) revealed that particles were spherical and presented a rough surface. NE formed a monodispersed population and no visible aggregates were present. However, at the lowest NE (3.4\%) and TR (0.5\%) concentrations an increase in particle size $(154 \mathrm{~nm})$ was observed. TEM (Fig. 7D) showed that particles were highly agglomerated. Low NE content formulations exhibited a poor aptness to freeze-drying. When the powder of TR (5\%) was dissolved in NE suspension (27\%), large $(190 \mathrm{~nm})$ and highly polydisperse $(\mathrm{Pdl}=0.4)$ particles were obtained, revealing a partial destabilization of the emulsion by TR. These results highlight the importance of the addition method (TR solution versus powder), which had to be considered as relevant during the freezing and drying steps.

In order to study whether the freeze-drying process could cause the leakage of the loaded drug, loaded NE were formulated, diluted at final NE concentration of $13.5 \%$, mixed with TR solution 
(2.5\%) and freeze-dried. A snow-like, smooth, elegant cake (Fig. 7C), with a low moisture content $(0.8 \%)$ was obtained. After rehydration, loaded NE physicochemical properties were maintained and corresponded to the ones of the freeze-dried blank NE (size $=146 \mathrm{~nm}, \mathrm{Pdl}=0.3$ ). $E E$ was $80 \%$, demonstrating the feasibility of freeze-drying loaded NE without drug leakage.

Overall, the highest yield of NE while preserving physicochemical properties was reached when 13.5\% NE was freeze-dried in presence of 2.5\% TR.

Recent studies report the successful lyophilisation of MCT-lecithin nanoemulsions at TR-NE ratio 10/1, while in this work same results were obtained at TR-NE ratio of 1/5 [55]. Our freeze-drying protocol benefits from using a low amount of cryoprotectant to dry a highest amount of lipid system. Such attribute cannot be found in previous research and can broaden the use of nanoemulsions in pharmaceutical applications. Globally, both freeze-drying and spray-drying were efficient in the conversion of NE into a dry powder. Although spray-drying is faster and less expensive than freezedrying, the high processing temperatures and the lowest quality of the dried products make the freeze-drying the preferred method for preserving the present pharmaceutical formulations. The highest process yields were obtained by freeze-drying. Indeed, there is no product collection step required after freeze-drying, thus avoiding product loss and contamination. A higher concentration of NE (13.5\% by freeze-drying versus $5 \%$ by spray-drying) was dried using lower amount of excipient (TR $2.5 \%)$.

\section{II.3.7. Structural characterization of nanoemulsions in colloidal suspension and reconstituted following drying processes}

A unique structural characterization of the NE, with an in-depth focus on the NE shell nature was performed. The shell composition, thickness and rigidity can affect nanoparticles stability and drug encapsulation efficacy [6]. So far, many studies on lipid-based systems focused on the characterization of crystalline or amorphous state of the oil core and on the link between drug loading efficacy and core properties [37]. The fluid or rigid nature of liposomes [38] and the rigid character of SLN or LNC composed of PEGylated surfactants [39] have been previously reported, but to our knowledge few studies have addressed the core-shell structure of NE [40]. The state of the shell (crystalline or amorphous) was presently investigated by means of DSC and XRPD measurements and the fluidity of the NE shell was assessed by fluorescence using a polarity-sensitive fluorophore. DSC analysis of the crystalline state of $N E(S M R=2.85, S O R=2.86)$ is shown in Fig. 8.3. Only evaporation of water was visible as NE was heated from room temperature up to $160^{\circ} \mathrm{C}$ (step 1). Once the sample was dry in the DSC pan, cooling caused crystallization, as revealed by an exotherm starting at $30{ }^{\circ} \mathrm{C}$ (step 2). Finally heating again caused melting at $40{ }^{\circ} \mathrm{C}$ (step 3). The exothermic and endothermic heats in the cooling step and heating steps were identical. DSC scans of single and physical mixtures of NE components were run in order to disclose which materials were involved

in

such

thermal

events. 

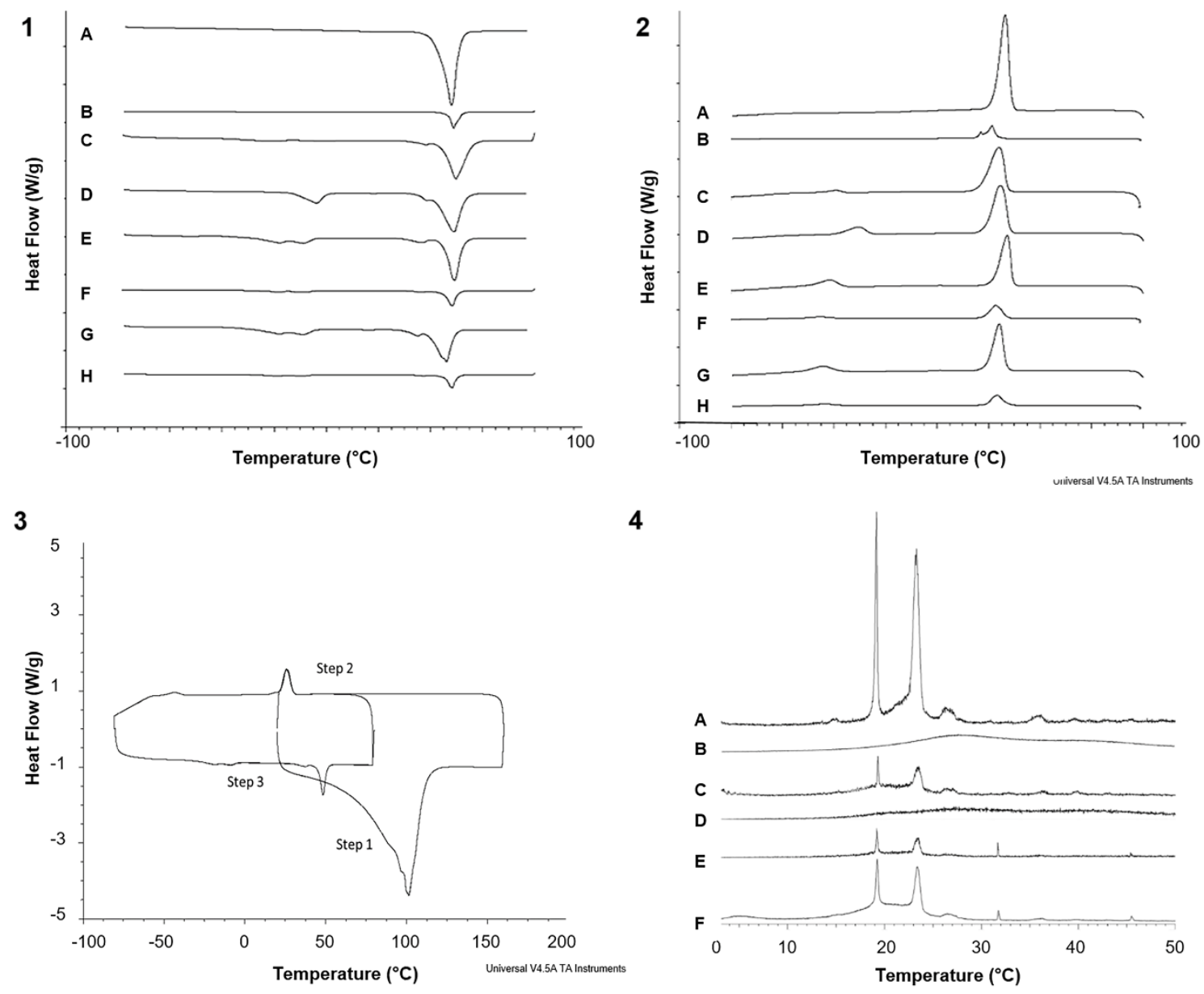

Fig. 81 and 2) DSC thermograms of: (A) S1 powder, (B) S1 in water solution, (C) mixture of S1 and S2 $(S M R=2.5),(D)$ mixture of $S 1$ and $M C T$, (E) oil phase: $S 1, S 2$ and $M C T,(F)$ blank $N E,(G)$ freeze-dried blank NE powder and $(\mathrm{H})$ freeze-dried blank NE re-suspended in water. Analysis performed from -80 ${ }^{\circ} \mathrm{C}$ to $+80^{\circ} \mathrm{C}$ at a $10^{\circ} \mathrm{C} \mathrm{min}-1$ rate. Data corresponding to the second cooling (1) and third heating (2) steps. 3) DSC thermogram of blank NE. Step 1: heating scan from $+20^{\circ} \mathrm{C}$ to $+160{ }^{\circ} \mathrm{C}$; step 2: cooling scan from $+80{ }^{\circ} \mathrm{C}$ to $-80^{\circ} \mathrm{C}$; step 3: heating scan from $-80^{\circ} \mathrm{C}$ to $+80^{\circ} \mathrm{C}$. 4) XRPD patterns of: (A) S1 powder, (B) S1 in water solution, (C)mixture of dry S1 and S2 (SMR=2.5), (D) blank NE in colloidal suspension, (E) blank NE after complete water evaporation, (F) freeze-dried blank NE powder.

Typical thermograms of NE and single components (after water evaporation) are displayed in Fig. 8.1 and 8.2. The solid crystalline hydrophilic surfactant $\mathrm{S} 1$, analysed as a powder, showed a melting endotherm at $43.1^{\circ} \mathrm{C}$ and a crystallization exotherm at $28.9^{\circ} \mathrm{C}$ upon cooling (Fig. 8.1 and 8.2, sample A). The same pattern was observed when $\mathrm{S} 1$ was dissolved in water, at a concentration of $14.28 \%$ (Fig. 8.1 and 8.2, sample B). Once S1 powder was mixed with liquid S2, no variation in the melting point was found for S1 (Fig. 8.1, sample $\mathrm{C}$ and Table 6). In addition to the main peak, a second peak at lower temperatures $\left(38^{\circ} \mathrm{C}\right.$ ) was observed in mixtures of S1 and S2 (Fig. 8.1, sample C), S1 and MCT (Fig. 8.1, sample D) and in the oil phase of the NE (Fig. 8.1, sample E), suggesting the presence of a second crystalline phase, attributable to a polymorphic form of the stearic acid of S1. Polymorphism resulted from the different molecular packing of S1 when mixed with S2 and MCT excipients [37]. 
DSC was also employed to study the MCT behaviour. In the mixture of S1 and MCT upon cooling, the MCT crystallized at $-25.5^{\circ} \mathrm{C}$ (Fig. 8.2, sample D). The melting of the frozen MCT occurred at $-12.5^{\circ} \mathrm{C}$ (Fig.8.1, sample D). While when the MCT were in the oil phase (sample E) and in the NE (sample F), a decrease of its crystallization peak $\left(-37.9^{\circ} \mathrm{C}\right)$ and an appearance of a second melting peak $\left(-27.2^{\circ} \mathrm{C}\right)$ were observed. Such behaviour can be referred to MCT polymorphism $[37,41]$. However, the assignment of polymorphs to MCT needs further investigation.

Overall, the major characteristic peaks for S1 were still observed in melting and crystallization patterns of NE (Fig. 8.1 and 8.2, sample F), proving the crystalline nature of the PEGylated NE shell. While the liquid amorphous state of $\mathrm{S} 2$ and MCT was supposedly maintained after NE formulation. In accordance with our results, previous studied proved how surfactants used to stabilize LNC and SLN maintained their crystallinity upon interaction with the oil core composed of medium chain triglycerides [37,42].

Moreover, dried NE powders and dried NE rehydrated were analysed to examine the influence of the drying process on the structure of NE. Once water had been evaporated, the melting and crystallization peaks of S1 were visible in NE dried with both spray-drying and freeze-drying (Table 6), while rehydrated NE were amorphous in colloidal suspension. A shift in the melting and crystallization peaks of the spray-dried NE (Table 6) was observed due to the presence of MD cryoprotectant in the sample. Instead, in both freeze-dried NE powders and NE rehydrated (analysed in absence of cryoprotectant), the crystallinity of the NE shell was maintained, without significant variations compared to the formulation before drying, as shown in Fig. 8.1 and 8.2, samples $\mathrm{G}$ and $\mathrm{H}$. The degree of crystallinity was calculated from the ratio of the enthalpy of S1 in the NE to bulk S1 enthalpy. The use of raw S1 not $100 \%$ crystalline and the formation of polymorphs not present in the bulk material might explain the degree of crystallinity values higher than $100 \%$, as the melting enthalpy of the raw S1 was taken as reference (Table 6).

Table 6 DSC analysis from $-80{ }^{\circ} \mathrm{C}$ to $+160^{\circ} \mathrm{C}$ at a $10{ }^{\circ} \mathrm{C} \cdot \mathrm{min}-1$ heating rate. NE were analyzed at the second heating scan.

\begin{tabular}{llllll}
\hline Sample & $\operatorname{Tm}\left({ }^{\circ} \mathrm{C}\right)$ & $\mathbf{T c}\left({ }^{\circ} \mathrm{C}\right)$ & $\Delta E \mathrm{~m}\left(\mathrm{~J} \cdot \mathrm{g}^{-1}\right)$ & $\Delta E \mathrm{c}\left(\mathrm{J} \cdot \mathrm{g}^{-1}\right)$ & Crystallinity $(\%)$ \\
\hline S1 & 43.1 & 28.9 & 128.6 & 128.6 & 100.0 \\
S1 + S2 & 44.4 & 27.4 & 123.7 & 128.2 & 96.2 \\
S1 + MCT & 41.1 & 28.2 & 137.2 & 133.6 & 106.7 \\
Full oil phase & 45.1 & 29.4 & 136.3 & 137.3 & 105.9 \\
NE & 45.4 & 29.7 & 155.3 & 148.9 & 120.8 \\
Freeze-dried NE powder & 39.1 & 26.9 & 131.7 & 129.9 & 102.4 \\
Freeze-dried NE rehydrated & 45.4 & 27.2 & 111.1 & 109.5 & 86.4 \\
Spray-dried NE powder & 34.8 & -5.7 & 85.9 & 62.9 & 77.8 \\
Spray-dried NE rehydrated & 39.9 & -2.3 & 4.7 & 6.0 & 77.8 \\
\hline
\end{tabular}

However, information about the crystalline state of NE while in colloidal suspension could not be provided due to the lack of sensitivity of the DSC technique in analysing samples in their wet state.

Thus, XRPD experiments (Fig. 8.4) were performed to further study the state of S1 in the NE shell and confirm the components behaviour established by DSC measurements. Bulk S1 (Fig. 8.4A) exhibited 
several diffraction reflections with two major sharp peaks at diffraction angles $\left(2 \theta=19.1^{\circ}\right.$ and $\left.23.2^{\circ}\right)$, indicating its crystalline state. The same peaks were observed in the mixture of S1 and S2 and in the NE after complete water evaporation (Fig. 8.4C and E, respectively). Similar peaks were also observed in the freeze-dried NE powder (Fig. 8.4F), demonstrating the aptness to freeze-drying of developed nanosystem. However, there were no characteristic peaks for crystalline S1 in colloidal suspension of NE (Fig. 8.4D), suggesting the amorphous state of S1 in wet state after the EPI process.

The nature of the NE shell was highly influenced by the presence of water. The dry hydrophilic shell was crystalline (after water evaporation and for lyophilized samples) and it became amorphous when hydrated. In line with previous studies, the formation of a bulky amorphous PEG-water complex in colloidal NE suspension decreases the packing density of the surfactant to such an extent that the stearic chains are no longer crystalline. This is a possible explanation for the observed behaviour [43]. NE were stabilized using a surfactant (S1) which is solid at room and physiological temperature $\left(T_{\mathrm{m}}\right.$ of $\mathrm{S} 1=43^{\circ} \mathrm{C}$ ) rising doubts about the fluid or rigid nature of the amorphous NE shell.

Firstly, an in vitro release study of tacrolimus was carried out at $50{ }^{\circ} \mathrm{C}$. No differences in release pattern were observed compared to $37{ }^{\circ} \mathrm{C}$, though these temperatures were below and above surfactant melting point $\left(43^{\circ} \mathrm{C}\right)$. Thus, the surfactant shell should have been in its molten state at both temperatures, such that it did not significantly act as a barrier against drug release [44].

To confirm this result, fluorescence measurements using polarity sensitive fluorophores were performed. Laurdan (6-dodecanoyl-2-dimethylaminonaphthalene) is a polarity-sensitive fluorophore commonly used for the assessment of liposomes rigidity and the study of biological membranes. Yet, when incubated with NE solution, its fluorescence emission spectrum with a single peak at $440 \mathrm{~nm}$ was characteristic of a highly hydrophobic environment, suggesting that the fluorophore was inserted in the hydrophobic core of the NE. Therefore, we presently used a home-made derivative of Laurdan called Dioll (patent pending EPO19306175.1-1118) having an enhanced polarity allowing better insertion in the NE shell. Dioll was post-inserted in the NE shell by simple mixing the probe with the NE suspension (Dioll-NE). Insertion of Dioll in the NE shell was checked by measurements of emission spectra of controls. Due to the lack of fluorescence activity in hydrophilic environment, no fluorescence emission was detected when the probe was dissolved in water. Neither blank NE emitted fluorescence. A single peak at $440 \mathrm{~nm}$ was observed when Dioll was dissolved in MCT related to the radiative de-excitation of a "locally excited" state of Dioll in oil [16] (detailed information can be found in the supplementary section). Emission spectra of Dioll-NE at temperatures ranging from $5{ }^{\circ} \mathrm{C}$ to $37^{\circ} \mathrm{C}$ showed two peaks at $440 \mathrm{~nm}$ and $490 \mathrm{~nm}$, (Fig. 9), which, based on literature data on Laurdan [16], corresponded to fluorophore inserted into a rigid or a fluid environment, respectively, each band depending on the physical state of the medium and on the capacity of the probe to undergo interactions with the surrounding water molecules. So, we could conclude that Dioll was emitting from NE surfactant shell and not from the MCT core of NE. Indeed, the Dioll hydrophobic tail could be oriented towards the NE oil core, while the hydrophilic and fluorescent naphthalene moiety could be aligned with the PEG components of $\mathrm{S1}$, towards the surrounding water phase. NE size, PdI

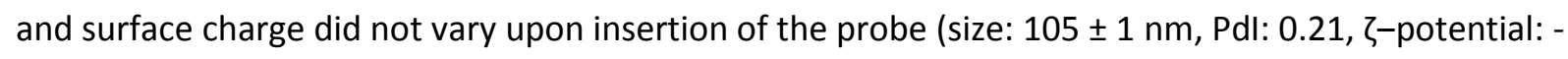
$18 \pm 1 \mathrm{mV})$. 

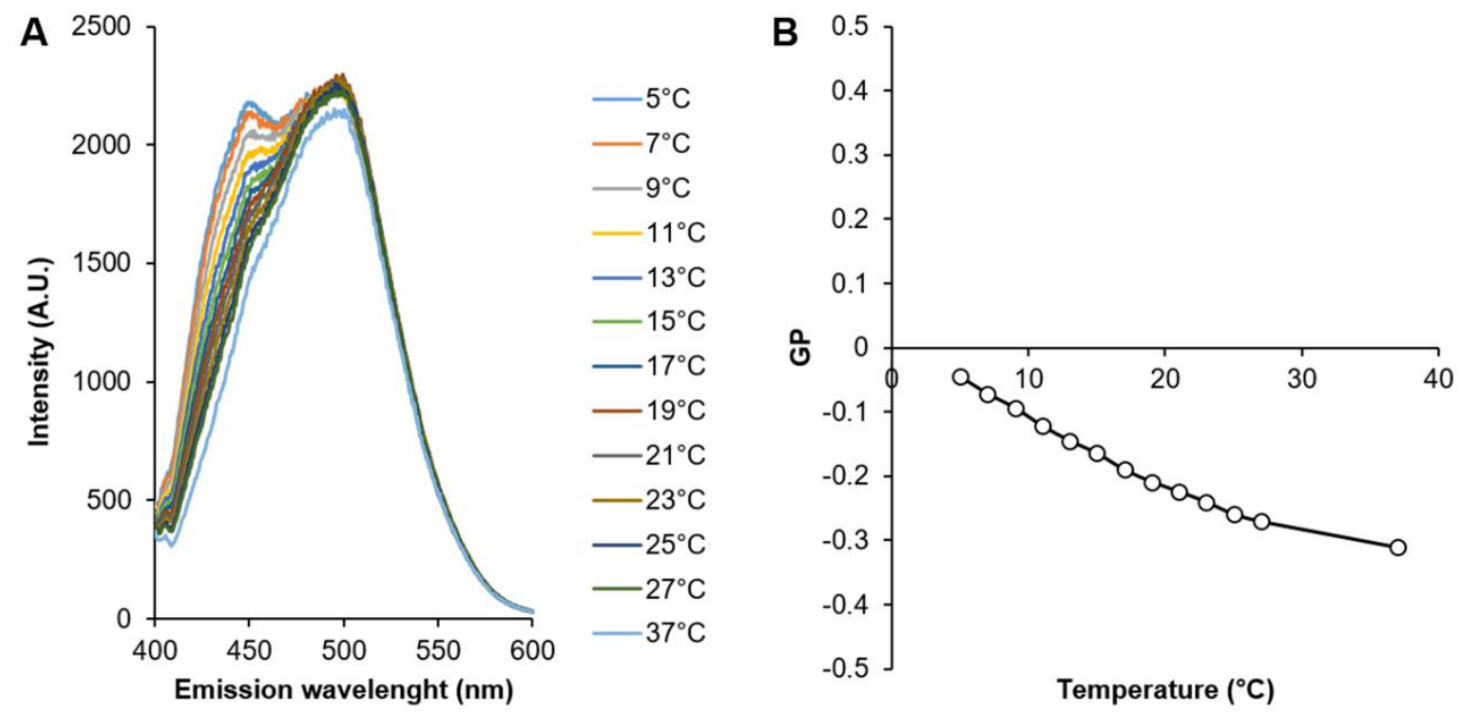

Fig. 9 A) Effect of temperature on fluorescence emission of Dioll-NE; B) Generalized Polarization of probes inserted in Dioll-NE as a function of temperature.

Decreasing the temperature from $37{ }^{\circ} \mathrm{C}$ to $5{ }^{\circ} \mathrm{C}$ led to the progressive increase of peak intensity at $440 \mathrm{~nm}$ (Fig. 9A). To quantify membrane fluidity state at each temperature, the GP values were calculated as described in Materials and methods section. GP increased as temperature was lowered (Fig. 9B), proving decreased fluidity of the NE shell. However, GP values remained negative (fluid state) and no significant phase transition from fluid to rigid state occurred over the full temperature range. The NE shell was in its fluid state, even at low temperature $\left(5^{\circ} \mathrm{C}\right)$.

NE differs from other LBDDS, such as LNC for the nature of the shell, which is fluid for NE and fairly rigid for LNC. The rigidity of the system is related to i) the presence of PEG as the outmost particle coating (i.e. lipidots, NLC, modified matrix SLN and mRNA-LNP $[39,40,45,46])$ and the density of PEG chains (PEG density is usually low for NE (<10 wt\%) and rather high (> $10 \mathrm{wt} \%)$ for LNC $[29,47])$; ii) the use of a solid excipient whose melting point is higher than the storage temperature [48]; iii) the overconcentration of surfactant on the NE surface, thanks to the stirring cycles performed, while formulating particles by the PIT method [48]. The presented NE should be rigid with regards to these three criteria. However, it was fluid according to fluorescence measurement. The fluidity of the NE shell is ascribed to the chemical structure of the S1 PEGylated surfactant that has a bulky head group that lowers the surfactant packing density in the membrane. S1 head groups weakened hydrophobic interactions between surfactant tails, thus constraining alkyl chains in a disordered configuration in order to fill the full space set by lateral steric repulsions between bulky PEG moieties [49]. Similar impact of the structure of system components on the final fluidity of the system has been described for liposomes. Liposomes composed of phosphatidic acid, which has a small head group, are rigid, while liposomes composed of phosphatidylcholine, which has a larger head group, are more fluid [50]. Moreover, the presence of the second surfactant (S2), which intercalates S1 in the NE shell, may further reduce the packing density of PEG chains $[25,51]$. 
We move that the latter shell characterization be performed on several lipid-based nanocarriers. Gained information on shell properties would patch the current structural analysis, whose main objective is the lipid core, leading to a better understanding of correlations between particle composition and stability, drug encapsulation efficacy, drug release behaviour. The whole set of physicochemical properties allows a proposal for the NE structure as described in Fig. 10.

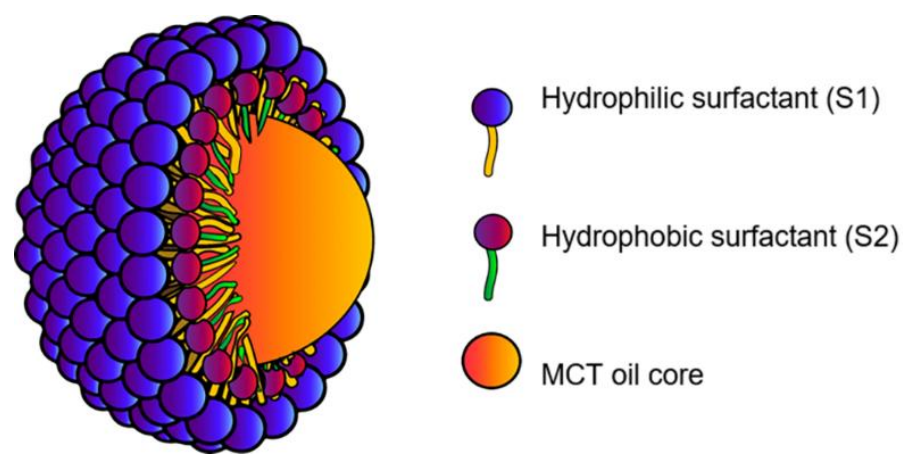

Fig. 10 Representation of the NE structure with oil core and mixed surfactant shell.

The oil liquid core corresponding to $\mathrm{MCT}$, was surrounded by a surfactant shell composed of a mixture of S1 and S2. S2 was located inside the mixed surfactant layer and its hydrophobic part interacts with the oil phase while the hydrophilic part of S1 was oriented to water.

\section{II.4. Conclusion}

In this work a novel approach of producing NE, based on the EPI method coupled with high energy input to shape droplets' size, was proposed. Through this innovative procedure, NE physicochemical properties were tuned to obtain systems which best suit the desired application.

Once the formulation criterion settled, the system composition was varied and optimized by mean of a robust experimental design over the full ternary phase diagram. The region of interest of suitable formulations was selected through the evaluation of parameters as the Smix surfactant ratio (SMR) and the surfactant-to-oil ratio (SOR). The ability of NE to efficiently encapsulate hydrophobic drug molecules (tacrolimus) and to modulate the release behaviour of the associated drug in biorelevant GI fluids was proven. To increase the shelf-life of the finished product by preserving it in a more stable dry state, NE were successfully converted into dry powders, using spray-drying and freezedrying techniques. Finally, the freeze-drying resulted as the most adequate technique, overcoming major challenges related with the production of dry powders from oil based systems. To study the shell nature (crystallinity and fluidity) of lipid nanocarriers, we have exploited an original methodology, based on combining DSC, XRD and an innovative fluorescence analysis. While, the fluidity of the NE shell was closely related to the structure of used excipients. Such structural analysis will supplement the usual characterization of nanocarriers, which is mostly focusing on the system core and loaded drug. Overall, the methodology and results here presented provide a template for developing a rational design of nanoemulsion-based systems intended for oral delivery of hydrophobic drugs. 


\section{Acknowledgements}

The research leading to these results has received funding from Agence Nationale de la Recherche, HyDNano project (ANR-18-CE18-0025-01) and from the Ministère de l'Enseignement Supérieur et de la Recherche (France)

\section{References}

[1] H. Mu, R. Holm, A. Müllertz, Lipid-based formulations for oral administration of poorly watersoluble drugs., Int. J. Pharm. 453 (2013) 215-24. doi:10.1016/j.ijpharm.2013.03.054.

[2] A. Müllertz, A. Ogbonna, S. Ren, T. Rades, New perspectives on lipid and surfactant based drug delivery systems for oral delivery of poorly soluble drugs, J. Pharm. Pharmacol. 62 (2010) 1622-1636. doi:10.1111/j.2042-7158.2010.01107.x.

[3] N. Matougui, L. Boge, A.-C. Groo, A. Umerska, L. Ringstad, H. Bysell, P. Saulnier, Lipid-based nanoformulations for peptide delivery, Int. J. Pharm. 502 (2016) 80-97. doi:10.1016/j.ijpharm.2016.02.019.

[4] H. Shrestha, R. Bala, S. Arora, Lipid-Based Drug Delivery Systems, J. Pharm. 2014 (2014) 1-10. doi:10.1155/2014/801820.

[5] F.U. Rehman, K.U. Shah, S.U. Shah, I.U. Khan, G.M. Khan, A. Khan, From nanoemulsions to self-nanoemulsions, with recent advances in self-nanoemulsifying drug delivery systems (SNEDDS), Expert Opin. Drug Deliv. $14 \quad$ (2017) 1325-1340. doi:10.1080/17425247.2016.1218462.

[6] N. Anton, J.-P. Benoit, P. Saulnier, Design and production of nanoparticles formulated from nano-emulsion templates-A review, J. Control. Release. 128 (2008) 185-199. doi:10.1016/j.jconrel.2008.02.007.

[7] C. Solans, I. Solé, Nano-emulsions: Formation by low-energy methods, Curr. Opin. Colloid Interface Sci. 17 (2012) 246-254. doi:10.1016/j.cocis.2012.07.003.

[8] J. Komaiko, D.J. McClements, Optimization of isothermal low-energy nanoemulsion formation: Hydrocarbon oil, non-ionic surfactant, and water systems, J. Colloid Interface Sci. 425 (2014) 59-66. doi:10.1016/j.jcis.2014.03.035.

[9] D.J. McClements, Edible nanoemulsions: fabrication, properties, and functional performance, Soft Matter. 7 (2011) 2297-2316. doi:10.1039/COSM00549E.

[10] N. Sadurní, C. Solans, N. Azemar, M.J. García-Celma, Studies on the formation of O/W nanoemulsions, by low-energy emulsification methods, suitable for pharmaceutical applications, Eur. J. Pharm. Sci. 26 (2005) 438-445. doi:10.1016/j.ejps.2005.08.001.

[11] A. Maali, M.T.H. Mosavian, Preparation and Application of Nanoemulsions in the Last Decade (2000-2010), J. Dispers. Sci. Technol. 34 (2013) 92-105. doi:10.1080/01932691.2011.648498.

[12] J.S. Komaiko, D.J. McClements, Formation of Food-Grade Nanoemulsions Using Low-Energy Preparation Methods: A Review of Available Methods, Compr. Rev. Food Sci. Food Saf. 15 (2016) 331-352. doi:10.1111/1541-4337.12189.

[13] F. Ostertag, J. Weiss, D.J. McClements, Low-energy formation of edible nanoemulsions: Factors influencing droplet size produced by emulsion phase inversion, J. Colloid Interface Sci. 388 (2012) 95-102. doi:10.1016/j.jcis.2012.07.089.

[14] S. Mayer, J. Weiss, D.J. McClements, Vitamin E-enriched nanoemulsions formed by emulsion phase inversion: Factors influencing droplet size and stability, J. Colloid Interface Sci. 402 (2013) 122-130. doi:10.1016/j.jcis.2013.04.016.

[15] M.M. Fryd, T.G. Mason, Advanced Nanoemulsions, Annu. Rev. Phys. Chem. 63 (2012) $493-$ 518. doi:10.1146/annurev-physchem-032210-103436.

[16] C.C. De Vequi-Suplicy, C.R. Benatti, M.T. Lamy, Laurdan in fluid bilayers: Position and structural sensitivity, J. Fluoresc. 16 (2006) 431-439. doi:10.1007/s10895-005-0059-3.

[17] A. Lamprecht, N. Ubrich, H. Yamamoto, U. Schäfer, H. Takeuchi, C.M. Lehr, P. Maincent, Y. Kawashima, Design of rolipram-loaded nanoparticles: Comparison of two preparation 
methods, J. Control. Release. 71 (2001) 297-306. doi:10.1016/S0168-3659(01)00230-9.

[18] International Conference on Harmonization of Technical Requirements for Registration of Pharmaceuticals for Human Use. Validation of Analytical Procedures: Text and Methodology, Q2 (R1), (2005).

[19] D. Zhang, X. Pan, S. Wang, Y. Zhai, J. Guan, Q. Fu, X. Hao, W. Qi, Y. Wang, H. Lian, X. Liu, Y. Wang, Y. Sun, Z. He, J. Sun, Multifunctional Poly(methyl vinyl ether-co-maleic anhydride)graft-hydroxypropyl- $\beta$-cyclodextrin Amphiphilic Copolymer as an Oral High-Performance Delivery Carrier of Tacrolimus, Mol. Pharm. 12 (2015) 2337-2351. doi:10.1021/acs.molpharmaceut.5b00010.

[20] E. Jantratid, N. Janssen, C. Reppas, J.B. Dressman, Dissolution Media Simulating Conditions in the Proximal Human Gastrointestinal Tract: An Update, Pharm. Res. 25 (2008) 1663-1676. doi:10.1007/s11095-008-9569-4.

[21] K.-O. Choi, N.P. Aditya, S. Ko, Effect of aqueous pH and electrolyte concentration on structure, stability and flow behavior of non-ionic surfactant based solid lipid nanoparticles, Food Chem. 147 (2014) 239-244. doi:10.1016/j.foodchem.2013.09.095.

[22] H. Scheffe, The Simplex-Centroid Design for Experiments with Mixtures, J. R. Stat. Soc. Ser. B. 25 (1963) 235-263. www.jstor.org/stable/2984294.

[23] H. Scheffé, Experiments with Mixtures, J. R. Stat. Soc. Ser. B. 21 (1959) 238-238. doi:10.1111/j.2517-6161.1959.tb00335.x.

[24] A.H. Saberi, Y. Fang, D.J. McClements, Fabrication of vitamin E-enriched nanoemulsions: Factors affecting particle size using spontaneous emulsification, J. Colloid Interface Sci. 391 (2013) 95-102. doi:10.1016/j.jcis.2012.08.069.

[25] D.J. McClements, S.M. Jafari, Improving emulsion formation, stability and performance using mixed emulsifiers: A review, Adv. Colloid Interface Sci. 251 (2018) 55-79. doi:10.1016/j.cis.2017.12.001.

[26] T. Schmidts, D. Dobler, A.C. Guldan, N. Paulus, F. Runkel, Multiple W/O/W emulsions-Using the required HLB for emulsifier evaluation, Colloids Surfaces A Physicochem. Eng. Asp. 372 (2010) 48-54. doi:10.1016/j.colsurfa.2010.09.025.

[27] J. Kuntsche, J.C. Horst, H. Bunjes, Cryogenic transmission electron microscopy (cryo-TEM) for studying the morphology of colloidal drug delivery systems, Int. J. Pharm. 417 (2011) 120137. doi:10.1016/j.ijpharm.2011.02.001.

[28] G. Li, Y. Fan, C. Fan, X. Li, X. Wang, M. Li, Y. Liu, Tacrolimus-loaded ethosomes: Physicochemical characterization and in vivo evaluation, Eur. J. Pharm. Biopharm. 82 (2012) 49-57. doi:10.1016/j.ejpb.2012.05.011.

[29] N.T. Huynh, C. Passirani, P. Saulnier, J.P. Benoit, Lipid nanocapsules: A new platform for nanomedicine, Int. J. Pharm. 379 (2009) 201-209. doi:10.1016/j.ijpharm.2009.04.026.

[30] Y. Wang, Y. Zheng, L. Zhang, Q. Wang, D. Zhang, Stability of nanosuspensions in drug delivery, J. Control. Release. 172 (2013) 1126-1141. doi:10.1016/j.jconrel.2013.08.006.

[31] P. Tewa-Tagne, S. Briançon, H. Fessi, Preparation of redispersible dry nanocapsules by means of spray-drying: Development and characterisation, Eur. J. Pharm. Sci. 30 (2007) 124-135. doi:10.1016/j.ejps.2006.10.006.

[32] A.R.D.V. Morais, É.D.N. Alencar, F.H. Xavier Júnior, C.M. De Oliveira, H.R. Marcelino, G. Barratt, H. Fessi, E.S.T. Do Egito, A. Elaissari, Freeze-drying of emulsified systems: A review, Int. J. Pharm. 503 (2016) 102-114. doi:10.1016/j.ijpharm.2016.02.047.

[33] H.H. Myat, G.C. Ritthidej, Impact of formulation parameters on physical characteristics of spray dried nanoemulsions and their reconstitutions, Asian J. Pharm. Sci. 11 (2016) 197-198. doi:10.1016/j.ajps.2015.11.038.

[34] U. Klinkesorn, P. Sophanodora, P. Chinachoti, D.. McClements, Stability and rheology of corn oil-in-water emulsions containing maltodextrin, Food Res. Int. 37 (2004) 851-859. doi:10.1016/j.foodres.2004.05.001.

[35] M.C.L. Marchiori, A.F. Ourique, C. de B. da Silva, R.P. Raffin, A.R. Pohlmann, S.S. Guterres, R.C.R. Beck, Spray-Dried Powders Containing Tretinoin-Loaded Engineered Lipid-Core 
Nanocapsules: Development and Photostability Study, J. Nanosci. Nanotechnol. 12 (2012) 2059-2067. doi:10.1166/jnn.2012.5192.

[36] N.-O. Chung, M.K. Lee, J. Lee, Mechanism of freeze-drying drug nanosuspensions, Int. J. Pharm. 437 (2012) 42-50. doi:10.1016/j.ijpharm.2012.07.068.

[37] V. Jenning, A.F. Thünemann, S.H. Gohla, Characterisation of a novel solid lipid nanoparticle carrier system based on binary mixtures of liquid and solid lipids, Int. J. Pharm. 199 (2000) 167-177. doi:10.1016/S0378-5173(00)00378-1.

[38] M. Hirai, R. Kimura, K. Takeuchi, Y. Hagiwara, R. Kawai-Hirai, N. Ohta, N. Igarashi, N. Shimuzu, Structure of liposome encapsulating proteins characterized by $\mathrm{X}$-ray scattering and shellmodeling, J. Synchrotron Radiat. 20 (2013) 869-874. doi:10.1107/S0909049513020827.

[39] M. Garcia-Fuentes, M.J. Alonso, D. Torres, Design and characterization of a new drug nanocarrier made from solid-liquid lipid mixtures, J. Colloid Interface Sci. 285 (2005) 590-598. doi:10.1016/j.jcis.2004.10.012.

[40] C.L. Dora, L.F.C. Silva, J.-L. Putaux, Y. Nishiyama, I. Pignot-Paintrand, R. Borsali, E. LemosSenna, Poly(ethylene glycol) Hydroxystearate-Based Nanosized Emulsions: Effect of Surfactant Concentration on Their Formation and Ability to Solubilize Quercetin, J. Biomed. Nanotechnol. 8 (2012) 202-210. doi:10.1166/jbn.2012.1380.

[41] A.P.B. Ribeiro, M.H. Masuchi, E.K. Miyasaki, M.A.F. Domingues, V.L.Z. Stroppa, G.M. de Oliveira, T.G. Kieckbusch, Crystallization modifiers in lipid systems, J. Food Sci. Technol. 52 (2015) 3925-3946. doi:10.1007/s13197-014-1587-0.

[42] B. Heurtault, P. Saulnier, B. Pech, J.-E. Proust, J.-P. Benoit, A novel phase inversion-based process for the preparation of lipid nanocarriers., Pharm. Res. 19 (2002) 875-80. doi:10.1023/a:1016121319668.

[43] N.S. Murthy, Z. Zhang, S. Borsadia, J. Kohn, Nanospheres with a smectic hydrophobic core and an amorphous PEG hydrophilic shell: structural changes and implications for drug delivery, Soft Matter. 14 (2018) 1327-1335. doi:10.1039/C7SM02472J.

[44] V. Karavelidis, D. Giliopoulos, E. Karavas, D. Bikiaris, Nanoencapsulation of a water soluble drug in biocompatible polyesters. Effect of polyesters melting point and glass transition temperature on drug release behavior., Eur. J. Pharm. Sci. 41 (2010) 636-43. doi:10.1016/j.ejps.2010.09.004.

[45] M.A. Schubert, M. Harms, C.C. Müller-Goymann, Structural investigations on lipid nanoparticles containing high amounts of lecithin, Eur. J. Pharm. Sci. 27 (2006) 226-236. doi:10.1016/j.ejps.2005.10.004.

[46] M. Yanez Arteta, T. Kjellman, S. Bartesaghi, S. Wallin, X. Wu, A.J. Kvist, A. Dabkowska, N. Székely, A. Radulescu, J. Bergenholtz, L. Lindfors, Successful reprogramming of cellular protein production through mRNA delivered by functionalized lipid nanoparticles, Proc. Natl. Acad. Sci. 115 (2018) E3351-E3360. doi:10.1073/pnas.1720542115.

[47] S. Hirsjärvi, S. Dufort, J. Gravier, I. Texier, Q. Yan, J. Bibette, L. Sancey, V. Josserand, C. Passirani, J.-P. Benoit, J.-L. Coll, Influence of size, surface coating and fine chemical composition on the in vitro reactivity and in vivo biodistribution of lipid nanocapsules versus lipid nanoemulsions in cancer models, Nanomedicine Nanotechnology, Biol. Med. 9 (2013) 375-387. doi:10.1016/j.nano.2012.08.005.

[48] N. Anton, P. Gayet, J.-P. Benoit, P. Saulnier, Nano-emulsions and nanocapsules by the PIT method: An investigation on the role of the temperature cycling on the emulsion phase inversion, Int. J. Pharm. 344 (2007) 44-52. doi:10.1016/j.ijpharm.2007.04.027.

[49] A. Dickey, R. Faller, Examining the contributions of lipid shape and headgroup charge on bilayer behavior, Biophys. J. 95 (2008) 2636-2646. doi:10.1529/biophysj.107.128074.

[50] N. Kato, A. Ishijima, T. Inaba, F. Nomura, S. Takeda, K. Takiguchi, Effects of lipid composition and solution conditions on the mechanical properties of membrane vesicles, Membranes (Basel). 5 (2015) 22-47. doi:10.3390/membranes5010022.

[51] C. Zylberberg, S. Matosevic, Pharmaceutical liposomal drug delivery: a review of new delivery systems and a look at the regulatory landscape, Drug Deliv. 23 (2016) 3319-3329. 
doi:10.1080/10717544.2016.1177136.

[52] S. Hua, E. Marks, J.J. Schneider, S. Keely, Advances in oral nano-delivery systems for colon targeted drug delivery in inflammatory bowel disease: Selective targeting to diseased versus healthy tissue, Nanomedicine Nanotechnology, Biol. Med. 11 (2015) 1117-1132. doi:10.1016/j.nano.2015.02.018.

[53] R.B. Friedrich, F.A. Dimer, S.S. Guterres, R.C.R. Beck, A.R. Pohlmann, Nanoencapsulation of tacrolimus in lipid-core nanocapsules showed similar immunosuppressive activity after oral and intraperitoneal administrations, J. Biomed. Nanotechnol. 10 (2014) 1599-1609. doi:10.1166/jbn.2014.1842.

[54] S. Khan, M. Shaharyar, M. Fazil, S. Baboota, J. Ali, Tacrolimus-loaded nanostructured lipid carriers for oral delivery - Optimization of production and characterization, Eur. J. Pharm. Biopharm. 108 (2016) 277-288. doi:10.1016/j.ejpb.2016.07.017.

[55] S. Guerrero, M. Inostroza-Riquelme, P. Contreras-Orellana, V. Diaz-Garcia, P. Lara, A. VivancoPalma, A. Cárdenas, V. Miranda, P. Robert, L. Leyton, M.J. Kogan, A.F.G. Quest, F. OyarzunAmpuero, Curcumin-loaded nanoemulsion: a new safe and effective formulation to prevent tumor reincidence and metastasis, Nanoscale. 10 (2018) 22612-22622. doi:10.1039/C8NR06173D. 


\section{Supplementary Information}
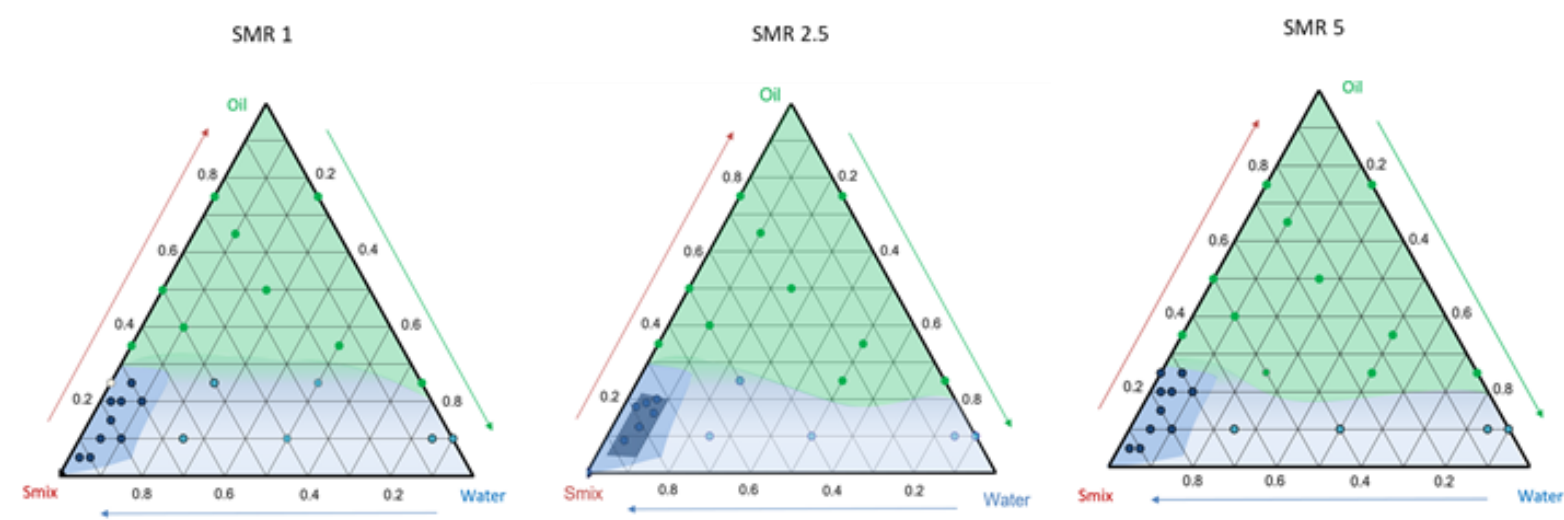

Fig. S1. Ternary phase diagram at $S M R=(A) 1$, (B) 2.5 , (C) 5 . The green area corresponds to formulations in the solid state, the two blue areas to formulations in the liquid state. The dark blue region corresponds to formulations containing NE.

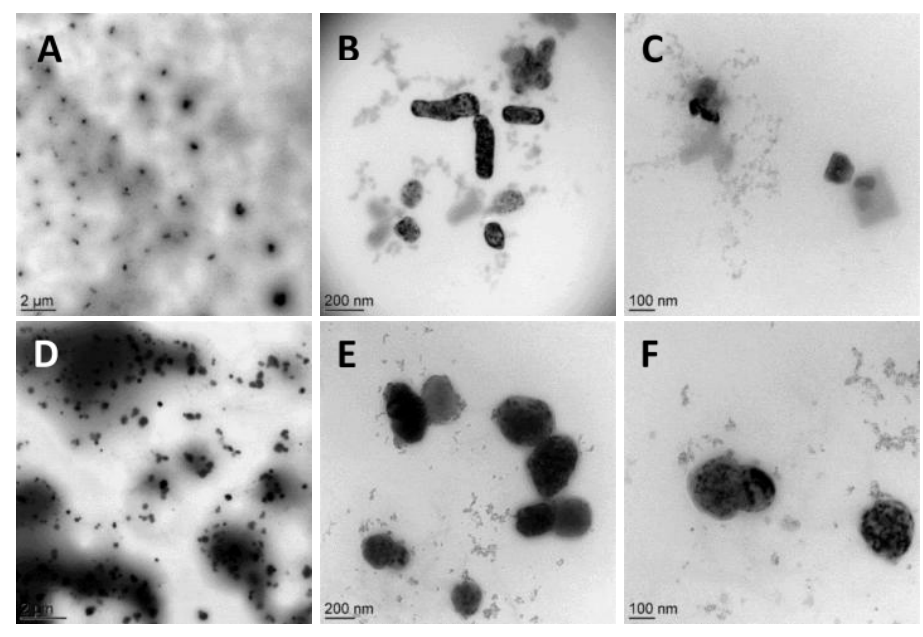

Fig. S2. TEM images of blank NE composed of S1 and S2 (without MCT) (A, B and C) and blank NE composed of S1 and MCT (without S2) (D, E, and F) at different magnifications (scales bars are $2 \mu \mathrm{m}$ ( $A$ and $D), 200 \mathrm{~nm}$ (B and $E$ ) and $100 \mathrm{~nm}(C$ and $F)$.

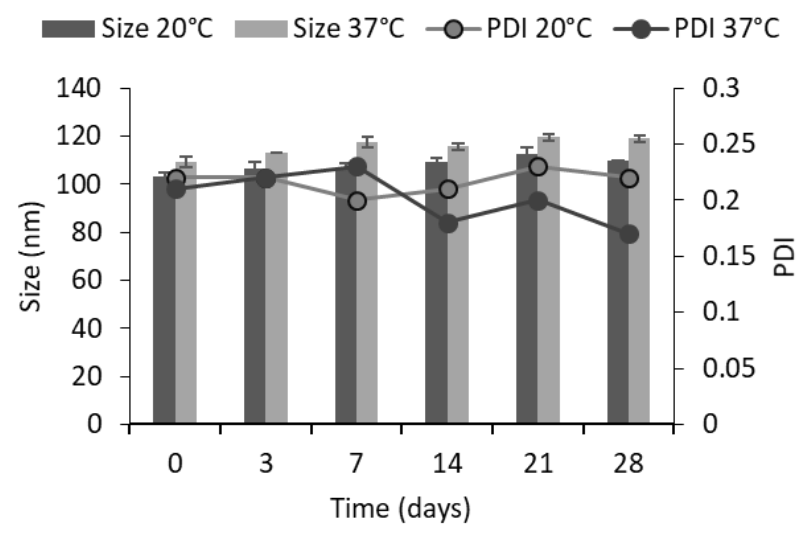

Fig. S3. Stability study of blank NE upon storage at $20^{\circ} \mathrm{C}$ and $37{ }^{\circ} \mathrm{C}$ for 28 days. Data are shown as mean \pm S.D., $n=3$. 


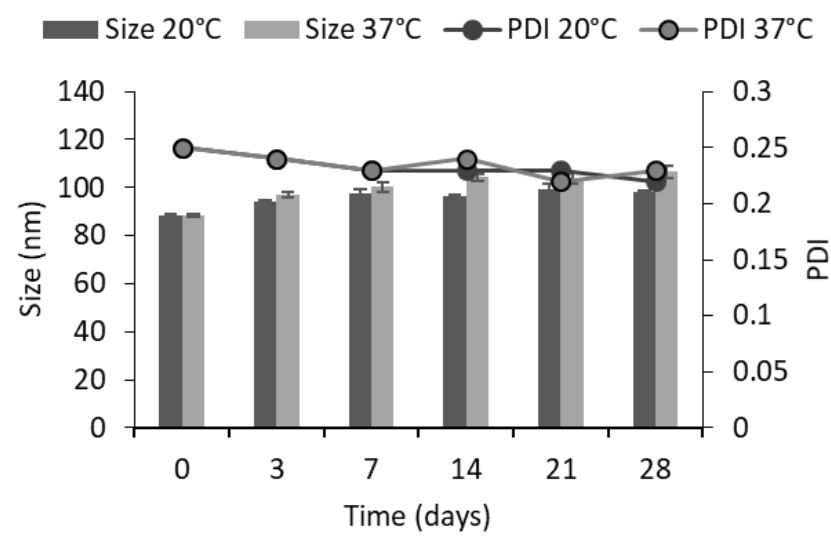

Fig. S4. Stability study of tacrolimus-NE upon storage at $20^{\circ} \mathrm{C}$ and $37^{\circ} \mathrm{C}$ for 28 days. Data are shown as mean \pm S.D., $n=3$.

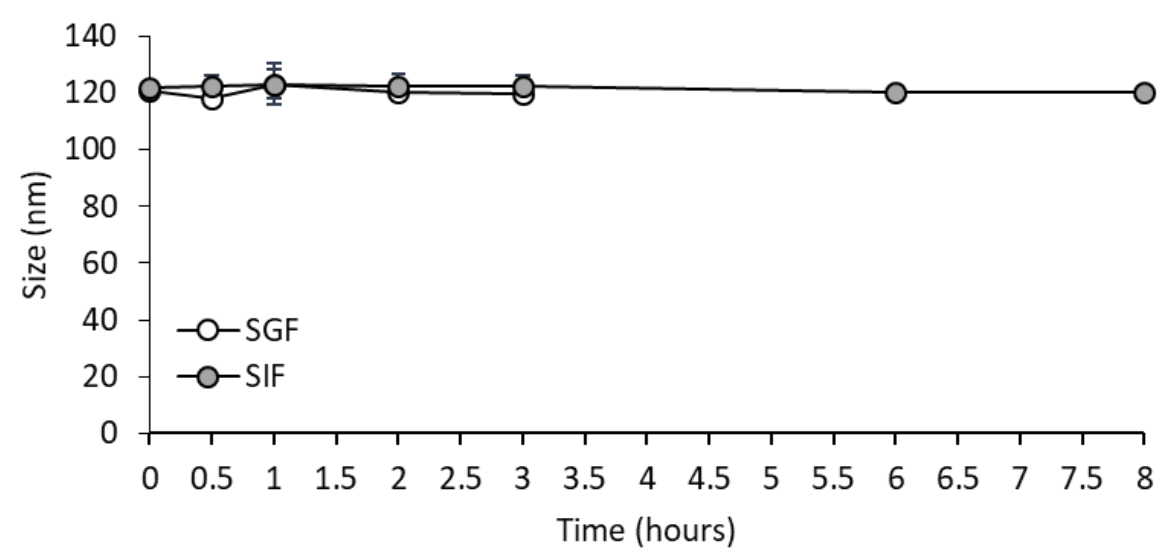

Fig. S5. Evolution of the particle size of tacrolimus-NE upon incubation in SGF and SIF media at $37^{\circ} \mathrm{C}$. The attenuator of the DLS instrument was fixed at 6 in the whole series of experiments. Mean \pm S.D., $n=3$. Original size of the formulation: $120.9 \pm 0.8 \mathrm{~nm}$. SGF: simulated gastric fluid; SIF: simulated intestinal fluid.

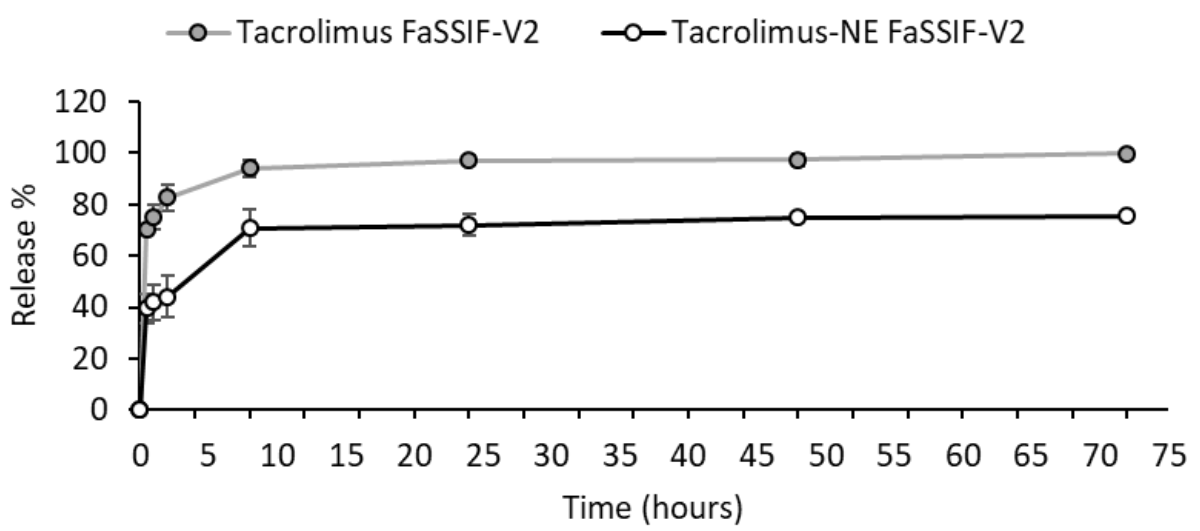

Fig. S6. In vitro release profiles of tacrolimus from solutions and loaded NE in FaSSIF-V2 (pH 6.5) up to $72 \mathrm{~h}$. Mean \pm SD, $n=3$. FaSSIF-V2: simulated intestinal fluid in fasted state. 


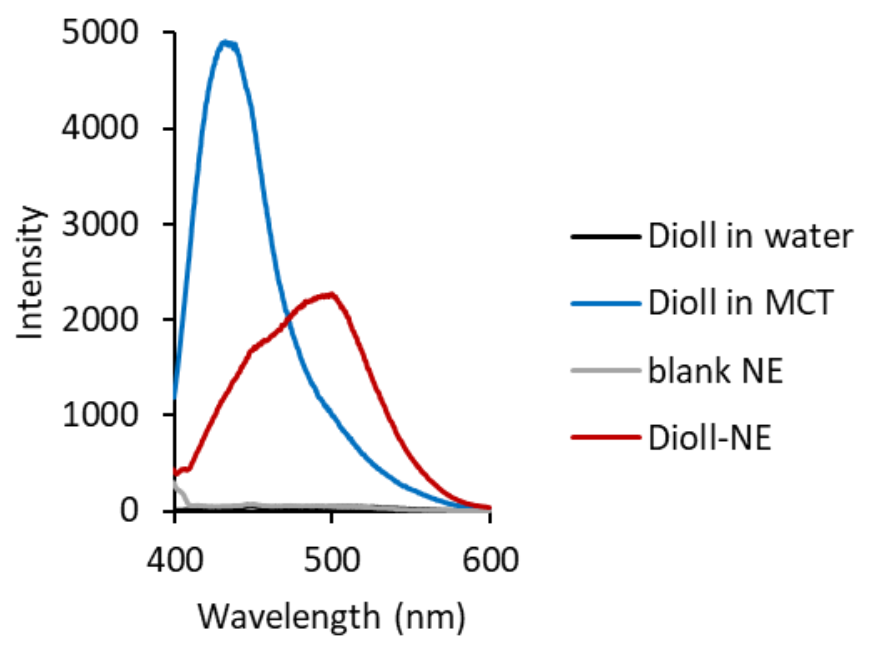

Fig. S7. Fluorescence emission spectra of Dioll-NE in control media at $21^{\circ} \mathrm{C}$ used as references for assessment of the effective insertion of Dioll in the NE shell.

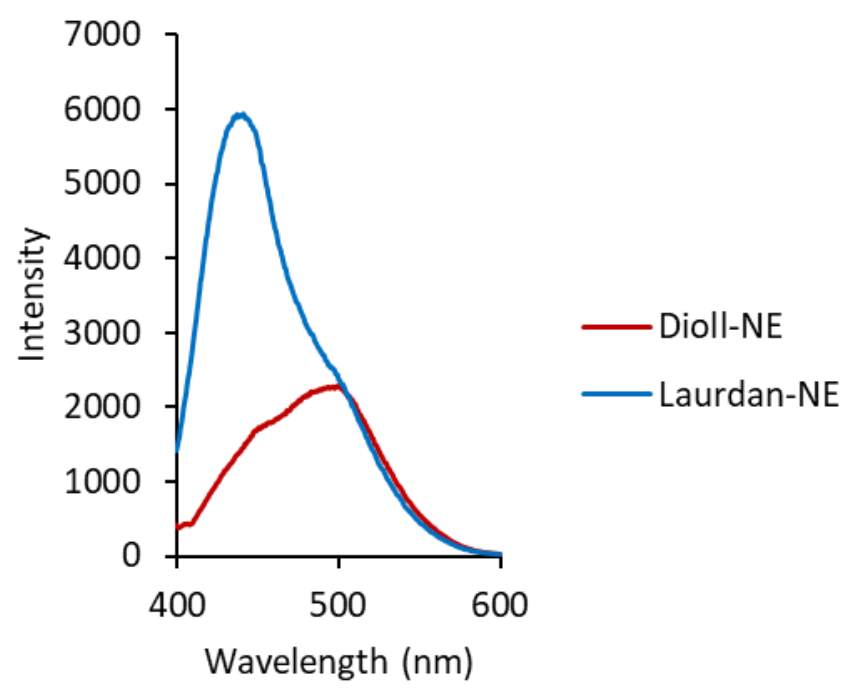

Fig. S8. Fluorescence emission spectra of Laurdan-NE versus Dioll-NE, showing the poor adequacy of the Laurdan probe in performing fluorescence measurements. Laurdan mostly inserted in the NE MCT core because of its highest hydrophobicity compared to Dioll, while Dioll was located in the NE shell. 